\title{
Human NK cell development in hIL-7 and hIL-15 knockin NOD/SCID/IL2rgKO mice
}

\author{
Masashi Matsudaํ, Rintaro Ono², Tomonori Iyoda ${ }^{3}$, Takaho Endo ${ }^{4}$, Makoto Iwasaki², Mariko Tomizawa-Murasawa ${ }^{2}$, \\ Yoriko Saito², Akiko Kaneko², Kanako Shimizu³ , Daisuke Yamada', Narumi Ogonuki ${ }^{5}$, Takashi Watanabe ${ }^{4}$, \\ Manabu Nakayama ${ }^{6}$, Yoko Koseki', Fuyuko Kezuka-Shiotani', Takanori Hasegawa', Hiromasa Yabe ${ }^{7}$, Shunichi Kato ${ }^{7}$, \\ Atsuo Ogura ${ }^{5}$, Leonard D Shultz ${ }^{8}$, Osamu Ohara ${ }^{4,6}$ (D, Masaru Taniguchi ${ }^{9}$, Haruhiko Koseki ${ }^{1}$, Shin-ichiro Fujii ${ }^{3}$, \\ Fumihiko Ishikawa ${ }^{2}$ (1)
}

The immune system encompasses acquired and innate immunity that matures through interaction with microenvironmental components. Cytokines serve as environmental factors that foster functional maturation of immune cells. Although NOD/ SCID/IL2rgKO (NSG) humanized mice support investigation of human immunity in vivo, a species barrier between human immune cells and the mouse microenvironment limits human acquired as well as innate immune function. To study the roles of human cytokines in human acquired and innate immune cell development, we created NSG mice expressing hIL-7 and hIL-15. Although hIL-7 alone was not sufficient for supporting human NK cell development in vivo, increased frequencies of human NK cells were confirmed in multiple organs of hIL-7 and hIL-15 double knockin (hIL-7xhIL-15 KI) NSG mice engrafted with human hematopoietic stem cells. hIL-7xhIL-15 KI NSG humanized mice provide a valuable in vivo model to investigate development and function of human NK cells.

DOI 10.26508/lsa.201800195 | Received 17 September 2018 | Revised 21 February 2019 | Accepted 22 February 2019 | Published online 1 April 2019

\section{Introduction}

Cytokine receptor signaling is indispensable for reconstitution of the human immune system following hematopoietic stem cell (HSC) therapy. Among multiple cytokines, IL-7 promotes differentiation and maturation of T cells, B cells (Mackall et al, 2011), and innate lymphoid cells (Moro et al, 2010). In addition to the development of mature lymphoid cells, IL-7 signaling plays a pivotal role at the level of progenitor cells. Studies of IL-7- or IL-7R-deficient mice revealed multiple defects in T- and B-cell development (Peschon et al, 1994; von Freeden-Jeffry et al, 1995). Defective IL-7R expression in humans results in $\mathrm{T}^{-} \mathrm{B}^{+} \mathrm{NK}^{+} \mathrm{SCID}$ (Puel et al, 1998).

IL-15 supports innate lymphoid cell development (Ali et al, 2015). Studies using IL-15 transgenic mice (Fehniger et al, 2001) and IL-15 knockout (IL-15KO) mice (Kennedy et al, 2000) have shown IL-15 to be essential in the development of NK cells, natural killer T (NKT) cells, and memory $\mathrm{CD}^{+} \mathrm{T}$ cells. Knocking out the genes encoding IL-15 or IL-15R $\alpha$ results in complete loss of NK cells in the thymus, BM, and spleen. NKT cells and CD44 ${ }^{\text {high }}$ memory phenotype $C D 8^{+} T$ cells were also reduced in IL-15KO and IL-15Ra knockout mice (Lodolce et al, 1998; Kennedy et al, 2000). A recent report demonstrated a role of IL-15 in anticancer immunity in that the frequencies of breast cancer metastasis were more frequent in IL-15KO mice than those in IL-15 transgenic mice or in C57BL/ 6 control mice (Gillgrass et al, 2014).

We developed NOD/SCID/IL2rgKO (NSG) mice to investigate the in vivo dynamics of the human immune system (Ishikawa et al, 2005; Shultz et al, 2005). In studies of humanized mice engrafted with human $\mathrm{HSC}$, we and others reported development of human T and B cells. However, the frequencies of human NK cells did not reach physiological levels in NSG humanized mice (Andre et al, 2010). The decreased NK cell development could be due to the species barrier between human lymphoid or NK cell progenitors and recipient microenvironment (Mestas \& Hughes, 2004).

To investigate the in vivo function of human IL-7 and IL-15 in the development of the human immune system, we created new strains of NSG mice expressing either hIL-7 alone (hIL-7TG NSG mice and hIL-7 KI NSG mice) and mice expressing hIL-7 and hIL-15 (hIL-7xhIL15 KI NSG mice). Analyses of these mice engrafted with human HSCS showed that hIL-15 is required for NK cell development. In addition,

\footnotetext{
${ }^{1}$ Laboratory for Developmental Genetics, RIKEN Center for Integrative Medical Sciences, Yokohama, Japan ${ }^{2}$ Laboratory for Human Disease Models, RIKEN Center for Integrative Medical Sciences, Yokohama, Japan ${ }^{3}$ Laboratory for Immunotherapy, RIKEN Center for Integrative Medical Sciences, Yokohama, Japan ${ }^{4}$ Laboratory for Integrative Genomics, RIKEN Center for Integrative Medical Sciences, Yokohama, Japan ${ }^{5}$ Bioresource Engineering Division, RIKEN BioResource Center, Tsukuba, Japan ${ }^{6}$ Department of Technology Development, Kazusa DNA Research Institute, Kisarazu, Japan ${ }^{7}$ Department of Cell Transplantation and Regenerative Medicine, Tokai University School of Medicine, Isehara, Japan ${ }^{8}$ The Jackson Laboratory, Bar Harbor, ME, USA ${ }^{9}$ Laboratory for Immune Regulation, RIKEN Center for Integrative Medical Sciences, Yokohama, Japan
} 
we found multiple subsets of human T cells in NSG recipient mice expressing human IL-7 and IL-15, demonstrating the roles of these cytokines in human T-cell development. These new humanized mouse models may support studies of human monoclonal antibody therapy in vivo and for studies of human acquired and innate tumor immunity.

\section{Results}

\section{Reconstitution of human immunity in the presence of hIL-7}

To study potential roles of human IL-7 in lymphoid cell development, we created hIL-7 KI and hIL-7 TG NSG mice. We first looked at effects of transgenic expression of human IL-7. When we compared reconstitution of T cells, B cells, and NK cells in the BM and spleen of cord blood (CB) HSC-engrafted NSG mice with or without expression of hIL-7, we did not find significant differences in the frequencies of each lineage within hCD $45^{+}$cells (NSG, $n=21$ : BM T cells $37.7 \pm 5.7 \%$, BM B cells $35.4 \pm 3.8 \%$, BM NK cells $1.0 \pm 0.2 \%$, spleen $T$ cells $48.1 \pm 4.8 \%$, spleen B cells $44.6 \pm 4.3 \%$, spleen NK cells $0.7 \pm 0.1 \%$; hIL-7 TG NSG, $n=3$ : BM T cells $28.7 \pm 27.1 \%$, BM B cells $42.0 \pm 18.9 \%$, BM NK cells $0.8 \pm 0.2 \%$, spleen T cells $38.5 \pm 23.5 \%$, spleen B cells $47.9 \pm 18.8 \%$, spleen NK cells $0.7 \pm 0.3 \%$; hIL-7 KI NSG, $n=4$ : BM T cells $11.4 \pm 5.9 \%$, BM B cells $29.8 \pm 8.9 \%$, BM NK cells $1.2 \pm$ $0.5 \%$, spleen T cells $53.4 \pm 11.3 \%$, spleen B cells $30.9 \pm 8.0 \%$, spleen NK cells $2.6 \pm 1.0 \%$; representative flow cytometry plots shown in Fig S1A and summarized data shown in Table S1). Because IL-7 has been reported to promote $B$-cell differentiation and maturation, we next evaluated human B-cell subsets in hIL-7 KI NSG humanized mice. In the BM, the majority of human $\mathrm{CD}_{19}{ }^{+}$cells were $\mathrm{CD}_{10}{ }^{+} \mathrm{CD} 20^{-}$pro- $\mathrm{B}$ cells, while $\mathrm{IgM}^{+} \mathrm{Ig} \mathrm{D}^{\text {low }}$ transitional and $\mathrm{IgM}^{+} \mathrm{IgD^{+ }}$ or IgM ${ }^{\text {low }} \mid g D^{+}$mature $B$ cells accounted for more than $70 \%$ of human $B$ cells in the spleen (representative flow cytometry plots shown in Fig S1B). The frequencies of human B-cell subsets were not altered significantly in hIL-7 KI NSG humanized mice (NSG, $n=4$ : $\mathrm{BM} \mathrm{CD} 10^{+} \mathrm{CD}_{20}{ }^{-}$cells $84.4 \pm 3.9 \%$, BM IgM ${ }^{+}$cells $23.7 \pm 2.6 \%$, spleen $\mathrm{CD}_{10}{ }^{+} \mathrm{CD} 20^{-}$cells $31.3 \pm 6.3 \%$, spleen IgM ${ }^{+}$cells $71.0 \pm 5.4 \%$; hIL-7 KI, $n=3: \mathrm{BM} \mathrm{CD} 10^{+} \mathrm{CD}^{-} 0^{-}$cells $81.9 \pm 1.9 \%$, BM IgM ${ }^{+}$cells $23.3 \pm 5.9 \%$, spleen $\mathrm{CD}_{10}{ }^{+} \mathrm{CD} 20^{-}$cells $21.0 \pm 5.4 \%$, spleen $\mathrm{IgM}^{+}$cells $73.4 \pm 2.1 \%$; summarized data shown in Table S2).

\section{Reconstitution of human immunity in the presence of hIL-7 and hIL-15}

To examine the role of hIL-15 and hIL-7 in human immune cell development, a new strain of NSG mice expressing hIL-15 and both hIL-7 and hIL-15 (hIL-7xhIL-15 KI NSG) were created. Plasma concentrations of human IL-7 and human IL-15 in hIL-7xhIL-15 KI NSG mice $(n=8)$ were $1.9 \pm 0.3 \mathrm{pg} / \mathrm{ml}$ and $87.8 \pm 9.8 \mathrm{pg} / \mathrm{ml}$, respectively (Fig S2). We then reconstituted human immunity by intravenously injecting $2.5 \times 10^{3}$ to $2.6 \times 10^{4} \mathrm{CB} \mathrm{CD} 4^{+} \mathrm{CD}_{3} 8^{-} \mathrm{CD}_{45 \mathrm{RA}^{-}}$

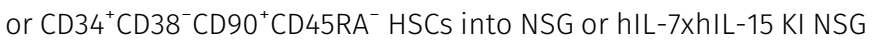
newborns (Table 1). In the recipient $B M$, thymus, spleen, and peripheral blood (PB), we found significantly higher frequencies of human $\mathrm{CD}^{+}{ }^{+}$NK cells in hIL-7xhIL-15 KI NSG humanized mice compared with conventional NSG humanized mice (NSG, $n=21$ : BM NK cells $1.0 \pm 0.2 \%$, spleen NK cells $0.7 \pm 0.1 \%$, PB NK cells $1.0 \pm 0.2 \%$; hIL-7xhIL-15 KI NSG, $n=17$ : BM NK cells $17.7 \pm 4.7 \%$, spleen NK cells $28.3 \pm 5.3 \%$, PB NK cells $43.1 \pm 5.4 \%$; NSG, $n=18$ : thymus NK cells $0.8 \pm$ $0.2 \%$; and hIL-7xhIL-15 KI NSG, $n=13$ : thymus NK cells $7.2 \pm 1.4 \%$. $P<$ 0.001 in BM, spleen, PB, and thymus, by two-tailed $t$ test; Fig $1 \mathrm{~A}-\mathrm{C}$, absolute numbers of cells are shown in Table S3). We confirmed efficient differentiation of human $\mathrm{CD}^{\circ} 6^{+} \mathrm{NK}$ cells in the BM, spleen, and PB of hIL-15 KI NSG humanized mice (representative flow cytometry plots shown in Fig S3 and summarized data shown in Table S4); therefore, we expected the presence of both hIL-7 and hIL-15 to further enhance development of human innate lymphoid cells.

hIL-15 has been reported to be secreted from myeloid cells (Cui et al, 2014) by trans-presentation (Stonier \& Schluns, 2010). Consistent with this, we confirmed expression of human IL-15 in Gra1 ${ }^{+}$ $\mathrm{Mac1}^{+}$mouse myeloid cells of hIL-7xhIL-15 KI NSG humanized mice, not in $\mathrm{CD}_{4} 5^{+} \mathrm{CD} 33^{+}$human myeloid cells or $\mathrm{Gra1}^{+} \mathrm{Mac1}^{+}$mouse myeloid cells purified from conventional NSG humanized mice (NSG $n=3$ and IL7XIL15 $n=3$; Fig 1D). In addition, we detected tissueresident NK cells such as CXCR6 ${ }^{+}$NK cells (Stegmann et al, 2016) in BM and liver of hIL-7xhIL-15 KI NSG humanized mice (BM $n=8$, Liver $n=5, \mathrm{~PB} n=4: \mathrm{BM} \mathrm{CXCR6}^{+} \mathrm{CD}^{2} 6^{+} \mathrm{NK}$ cells $67.6 \pm 2.3 \%$, liver $\mathrm{CXCR} 6^{+} \mathrm{CD}^{\circ} 6^{+}$ NK cells $10.2 \pm 5.1 \%$, PB CXCR6 ${ }^{+} \mathrm{CD}^{2} 6^{+} \mathrm{NK}$ cells $1.4 \pm 0.9 \%$; Fig $1 \mathrm{E}$ and $\mathrm{F}$ ).

In addition to human NK cell development, we examined whether the cytokines facilitate the development of human T cells or induce skewing of specific human T-cell subsets. To this end, we first analyzed development of human T-cell subsets in the thymus and spleen. Within the thymic $h \mathrm{CD}_{4} 5^{+} \mathrm{CD} 56^{-} \mathrm{CD} 3^{+}$fraction, we found higher frequency of $\mathrm{CD}^{-} \mathrm{CD}^{+}$single positive T cells in hIL-7xhIL-15 KI NSG humanized mice (NSG, $n=18$ : $\mathrm{CD}^{-} \mathrm{CD}^{+}$cells $15.6 \pm 3.1 \%$; hIL7xhIL-15 KI NSG, $n=12$ : $\mathrm{CD}^{-}{ }^{-} \mathrm{CD} 8^{+}$cells $59.5 \pm 5.9 \%$. $P<0.001$ by two-tailed $t$ test; Fig $2 \mathrm{~A}$ and $\mathrm{B}$, absolute numbers of cells are shown in Table S3).

Next, using spleen cells, we examined the frequencies of human $\mathrm{CD}^{+} \mathrm{T}, \mathrm{CD}^{+} \mathrm{T}$, and $\mathrm{CD} 8^{+} \mathrm{T}$ cells and their CD45RA and Foxp3 expression in NSG and hIL-7xhIL-15 KI NSG humanized mice (representative flow cytometry plots shown in Fig $2 \mathrm{C}$ ). We found that both $\mathrm{CD}_{45 A^{+}}$naive and CD45RA- memory T cells were present in $\mathrm{CD}^{+} \mathrm{T}$ or $\mathrm{CD}^{+}{ }^{+}$-cell populations of hIL-7xhIL-15 KI NSG humanized mice (NSG, $n=7: \mathrm{CD}^{+} \mathrm{CD}^{2} 5 \mathrm{RA}^{+}$cells $3.3 \pm 1.0 \%, \mathrm{CD}^{+} \mathrm{CD}^{\mathrm{C}} 5 \mathrm{RA} \mathrm{A}^{-}$cells $96.7 \pm$ $1.0 \%, \mathrm{CD}^{+} \mathrm{CD}^{2} 5 \mathrm{RA}^{+}$cells $30.6 \pm 6.6 \%, \mathrm{CD}^{+} \mathrm{CD}^{2} 5 \mathrm{RA}^{-}$cells $69.5 \pm 6.6 \%$; hIL-7xhIL-15 KI NSG, $n=5$ : $\mathrm{CD}^{+} \mathrm{CD}^{2} 5 \mathrm{RA}^{+}$cells $11.3 \pm 6.7 \%$, $\mathrm{CD}^{+}{ }^{+}$CD 45RA ${ }^{-}$cells $88.7 \pm 6.8 \%, \mathrm{CD}^{+} \mathrm{CD}^{-} 5 \mathrm{RA}{ }^{+}$cells $37.0 \pm 17.2 \%, \mathrm{CD}^{+}$ CD45RA cells $63.0 \pm 17.2 \%$; Fig 2D). Frequencies of splenic $\mathrm{CD}^{+}$and $\mathrm{CD}^{+} \mathrm{T}$ cells in $\mathrm{CD}^{+} \mathrm{T}$ cells are shown in Fig 2D (NSG, $n=7: \mathrm{CD}^{+}$cells $72.8 \pm 3.1 \%$, CD8 ${ }^{+}$cells $21.5 \pm 3.0 \%$; hIL-7xhIL-15 KI NSG, $n=5: \mathrm{CD}^{+}$cells $61.9 \pm 4.7 \%, \mathrm{CD}^{+}$cells $31.6 \pm 3.5 \% . P=0.068$ in $\mathrm{CD}^{+}$cells and $P=0.052$ in $\mathrm{CD}^{+}$cells by two-tailed $t$ test; Fig 2D). Frequency of Foxp $3^{+}$cells in $\mathrm{CD}^{+} \mathrm{T}$ cells was similar between NSG and hIL-7xhIL-15 KI NSG humanized mice (NSG, $n=7: 8.8 \pm 1.5 \%$; hIL-7xhIL-15 KI NSG, $n=5: 6.5 \pm$ 2.4\%. $P=0.41$ by two-tailed $t$ test). Although we found enhanced human NK cells and T-cell development in hIL-7xhIL-15 KI NSG humanized mice, TCRV $\alpha 24^{+} V \beta 11^{+} \mathrm{CD}^{+} \mathrm{NKT}$ cells were not detected (representative flow cytometry plots in Fig 2E). This suggests that hIL-7 and hIL-15 play distinct roles in the development of human NK and NKT cells. 
Table 1. Engraftment of human leukocytes in NSG mice expressing hIL-7 and/or hIL-15.

\begin{tabular}{|c|c|c|c|c|c|c|c|c|c|c|c|c|c|}
\hline \multirow{2}{*}{ Mouse ID } & \multirow{2}{*}{ CB ID } & \multirow{2}{*}{ Strain } & \multirow{2}{*}{ Week $^{a}$} & \multicolumn{5}{|c|}{ Spleen, \% } & \multicolumn{5}{|l|}{$\mathrm{PB}, \%$} \\
\hline & & & & hCD $45+^{b}$ & CD56+ & CD3+ & CD19+ & CD33+ & hCD $45+^{b}$ & CD56+ & CD3+ & CD19+ & CD33+ \\
\hline IL7x15\#1 & $\mathrm{CB} \# 1$ & hIL-7xhIL-15 KI & 15 & 46.6 & 35.3 & 11.4 & 19.2 & 15.3 & 15.0 & 60.4 & 6.5 & 2.4 & 6.1 \\
\hline IL7X15\#3 & $\mathrm{CB} \# 2$ & hIL-7xhIL-15 KI & 10 & 98.1 & 13.0 & 0.1 & 78.8 & 3.1 & 93.6 & 38.5 & 0.3 & 42.2 & 7.8 \\
\hline IL7X15\#4 & $\mathrm{CB} \# 2$ & hIL-7xhIL-15 KI & 16 & 92.7 & 3.8 & 23.5 & 57.8 & 5.7 & 95.9 & 19.2 & 37.4 & 15.4 & 10.1 \\
\hline IL7x15\#6 & $\mathrm{CB} \# 4$ & hIL-7xhIL-15 KI & 19 & 77.7 & 22.1 & 2.5 & 49.0 & 4.1 & 30.4 & 37.7 & 2.5 & 26.7 & 4.9 \\
\hline IL7x15\#7 & $\mathrm{CB} \# 4$ & hIL-7xhIL-15 KI & 22 & 66.8 & 26.0 & 26.8 & 26.5 & 3.6 & 18.8 & 38.3 & 33.1 & 21.0 & 1.4 \\
\hline IL7X15\#8 & $\mathrm{CB} \# 4$ & hIL-7xhIL-15 KI & 23 & 64.4 & 16.2 & 10.1 & 16.2 & 6.6 & 15.7 & 6.0 & 18.2 & 24.3 & 3.1 \\
\hline IL7X15\#9 & CB\#5 & hIL-7xhIL-15 KI & 13 & 80.6 & 36.6 & 1.7 & 40.8 & 8.2 & 49.2 & 47.2 & 1.2 & 19.3 & 20.0 \\
\hline IL7X15\#10 & $\mathrm{CB} \# 6$ & hIL-7xhIL-15 KI & 19 & 65.9 & 52.9 & 1.0 & 17.3 & 14.5 & 30.8 & 64.9 & 0.6 & 6.9 & 8.3 \\
\hline IL7X15\#14 & $\mathrm{CB} \# 9$ & hIL-7xhIL-15 KI & 20 & 28.8 & 56.0 & 2.5 & 11.5 & 9.2 & 11.6 & 70.2 & 1.4 & 7.6 & 10.5 \\
\hline IL7X15\#15 & $\mathrm{CB} \# 10$ & hIL-7xhIL-15 KI & 11 & 78.7 & 9.4 & 0.4 & 76.1 & 5.1 & 77.1 & 25.2 & 0.3 & 34.7 & 27.9 \\
\hline IL7x15\#16 & CB\#11 & hIL-7xhIL-15 KI & 15 & 58.7 & 72.8 & 1.1 & 12.9 & 6.7 & 7.4 & 68.8 & 0.0 & 8.5 & 15.3 \\
\hline IL7X15\#17 & $\mathrm{CB} \# 12$ & hIL-7xhIL-15 KI & 15 & 74.1 & 54.1 & 0.8 & 27.8 & 8.1 & 20.1 & 55.4 & 0.9 & 20.8 & 2.0 \\
\hline IL7X15\#18 & $\mathrm{CB} \# 13$ & hIL-7xhIL-15 KI & 8 & 68.9 & 25.6 & 0.0 & 54.1 & 7.8 & 7.7 & 24.6 & 0.0 & 29.1 & 33.0 \\
\hline IL7x15\#19 & CB\#14 & hIL-7xhIL-15 KI & 16 & 23.9 & 87.5 & 0.5 & 7.6 & 1.5 & 2.2 & 82.8 & 0.8 & 5.5 & 3.1 \\
\hline IL7X15\#20 & CB\#15 & hIL-7xhIL-15 KI & 9 & 56.9 & 31.3 & 0.0 & 32.3 & 22.5 & 35.9 & 60.0 & 0.1 & 8.2 & 18.2 \\
\hline IL7x15\#21 & CB\#16 & hIL-7xhIL-15 KI & 11 & 46.5 & 61.5 & 1.2 & 24.1 & 3.6 & 31.2 & 70.7 & 1.2 & 12.4 & 4.9 \\
\hline IL7TG\#5 & CB\#15 & hIL-7 Tg & 16 & 97.8 & 1.2 & 8.0 & 58.6 & 22.2 & 92.3 & 1.7 & 32.1 & 25.2 & 26.2 \\
\hline IL7TG\#6 & $\mathrm{CB} \# 16$ & hIL-7 Tg & 12 & 81.0 & 0.6 & 2.5 & 73.9 & 8.5 & 93.1 & 0.7 & 2.2 & 73.9 & 14.4 \\
\hline IL7TG\#7 & CB\#17 & hIL-7 Tg & 24 & 95.6 & 0.3 & 2.1 & 11.3 & 84.9 & 81.9 & 0.3 & 0.2 & 2.8 & 95.4 \\
\hline NSG\#1 & CB\#1 & NSG & 20 & 79.8 & 0.3 & 48.6 & 40.1 & 1.6 & 43.6 & 0.2 & 91.1 & 5.0 & 0.7 \\
\hline NSG\#2 & $\mathrm{CB} \# 2$ & NSG & 17 & 78.1 & 0.2 & 77.5 & 19.1 & 1.4 & 68.5 & 0.2 & 96.9 & 1.0 & 0.2 \\
\hline NSG\#3 & $\mathrm{CB} \# 2$ & NSG & 18 & 85.9 & 0.6 & 14.8 & 74.5 & 3.9 & 37.8 & 0.6 & 50.8 & 28.9 & 11.4 \\
\hline NSG\#4 & $\mathrm{CB} \# 3$ & NSG & 18 & 90.3 & 1.2 & 7.5 & 76.7 & 6.4 & 59.8 & 1.2 & 15.2 & 51.6 & 17.2 \\
\hline NSG\#5 & $\mathrm{CB} \# 3$ & NSG & 19 & 92.4 & 1.2 & 20.5 & 72.4 & 3.5 & 81.5 & 2.5 & 44.0 & 44.3 & 3.6 \\
\hline NSG\#6 & $\mathrm{CB} \# 3$ & NSG & 20 & 91.7 & 1.1 & 10.8 & 72.6 & 5.4 & 68.1 & 1.0 & 28.2 & 36.7 & 22.4 \\
\hline NSG\#7 & CB\#5 & NSG & 18 & 71.6 & 0.9 & 52.4 & 47.9 & 1.2 & 37.4 & 0.8 & 74.5 & 20.5 & 1.7 \\
\hline NSG\#8 & CB\#5 & NSG & 19 & 90.2 & 0.2 & 77.6 & 24.0 & 0.9 & 79.9 & 0.6 & 89.2 & 7.0 & 2.3 \\
\hline NSG\#9 & CB\#7 & NSG & 17 & 98.8 & 0.1 & 64.8 & 30.9 & 1.2 & 97.9 & 0.6 & 83.3 & 10.6 & 0.3 \\
\hline NSG\#10 & CB\#8 & NSG & 19 & 88.6 & 2.3 & 40.9 & 48.2 & 6.4 & 36.1 & 1.9 & 46.1 & 42.9 & 4.9 \\
\hline NSG\#11 & CB\#8 & NSG & 19 & 88.5 & 0.7 & 35.3 & 58.1 & 4.8 & 39.4 & 0.3 & 46.6 & 48.7 & 2.3 \\
\hline NSG\#12 & $\mathrm{CB} \# 10$ & NSG & 20 & 98.6 & 0.1 & 60.2 & 32.1 & 0.8 & 97.0 & 0.5 & 85.5 & 7.7 & 1.3 \\
\hline
\end{tabular}


Table 1. Continued

\begin{tabular}{|c|c|c|c|c|c|c|c|c|c|c|c|c|c|}
\hline \multirow{2}{*}{ Mouse ID } & \multirow{2}{*}{ CB ID } & \multirow{2}{*}{ Strain } & \multirow{2}{*}{ Week $^{a}$} & \multicolumn{5}{|l|}{ Spleen, \% } & \multicolumn{5}{|l|}{ PB, \% } \\
\hline & & & & hCD45+ ${ }^{b}$ & CD56+ & CD3+ & CD19+ & CD33+ & hCD45+ ${ }^{b}$ & CD56+ & CD3+ & CD19+ & CD33+ \\
\hline NSG\#13 & $\mathrm{CB} \# 10$ & NSG & 20 & 93.9 & 0.8 & 56.7 & 38.7 & 3.2 & 79.8 & 2.3 & 78.8 & 7.2 & 5.6 \\
\hline NSG\#14 & $\mathrm{CB} \# 12$ & NSG & 19 & 84.4 & 1.0 & 37.8 & 55.8 & 3.3 & 56.7 & 0.9 & 54.1 & 41.7 & 1.6 \\
\hline NSG\#15 & $\mathrm{CB} \# 12$ & NSG & 21 & 85.1 & 0.7 & 40.4 & 53.1 & 2.7 & 49.9 & 0.7 & 56.0 & 34.7 & 3.8 \\
\hline NSG\#16 & CB\#13 & NSG & 22 & 95.9 & 0.2 & 75.9 & 13.4 & 2.2 & 97.4 & 0.4 & 90.0 & 2.2 & 3.6 \\
\hline NSG\#17 & $\mathrm{CB} \# 13$ & NSG & 23 & 78.5 & 1.8 & 61.8 & 27.1 & 3.9 & 28.5 & 4.3 & 64.8 & 18.9 & 3.5 \\
\hline NSG\#18 & CB\#14 & NSG & 21 & 82.1 & 0.4 & 38.8 & 56.4 & 2.3 & 31.5 & 0.2 & 63.3 & 29.1 & 3.4 \\
\hline NSG\#19 & CB\#18 & NSG & 17 & 93.7 & 0.7 & 55.3 & 38.9 & 1.5 & 62.0 & 1.0 & 75.8 & 18.5 & 1.8 \\
\hline NSG\#20 & CB\#18 & NSG & 19 & 83.3 & 0.6 & 49.7 & 43.9 & 0.9 & 66.1 & 0.6 & 88.9 & 6.3 & 0.1 \\
\hline NSG\#21 & $\mathrm{CB} \# 19$ & NSG & 20 & 99.7 & 0.3 & 83.0 & 13.4 & 1.4 & 99.0 & 0.5 & 90.9 & 4.9 & 1.5 \\
\hline NSG\#22 & $\mathrm{CB} \# 18$ & NSG & 19 & 89.9 & 1.7 & 54.5 & 36.5 & 2.1 & 64.7 & 1.4 & 76.5 & 18.1 & 1.4 \\
\hline NSG\#23 & CB\#18 & NSG & 19 & 93.6 & 0.5 & 16.0 & 79.6 & 1.0 & 81.7 & 0.5 & 20.2 & 76.7 & 0.2 \\
\hline NSG\#24 & CB\#19 & NSG & 17 & 87.0 & 2.0 & 46.4 & 45.1 & 3.3 & 42.8 & 7.0 & 65.9 & 14.1 & 2.8 \\
\hline
\end{tabular}

${ }^{a}$ Number of weeks after CB transplantation when euthanized are shown.

${ }^{b}$ Frequencies of human CD45+ cells in total leukocytes including human and mouse CD45+ cells.

\section{Maturation and location of human NK cells in hIL-7xhIL-15 KI NSG humanized mice}

After the development of human NK cells in the primary immune organs (BM and thymus), they undergo maturation in peripheral organs such as spleen (Freud et al, 2014; Bjorkstrom et al, 2016). We analyzed frequencies of human NK cells and assessed the degree of maturation in hIL7xhIL15 KI NSG humanized mice. Among $\mathrm{CD}_{56}{ }^{+}$cells, we found significantly higher percentages of human $\mathrm{CD} 56^{+} \mathrm{CD} 94^{+} \mathrm{CD} 16^{+}$relatively mature NK cells in the spleen and PB of the hIL-7xhIL-15 KI NSG humanized mice compared with NSG humanized mice (NSG, $n=20$ : BM CD94 ${ }^{+} \mathrm{CD}_{16}{ }^{+}$cells $28.8 \pm 4.7 \%$, spleen $\mathrm{CD} 4^{+} \mathrm{CD} 16^{+}$cells $27.2 \pm 2.8 \%$; hIL-7xhIL-15 KI NSG, $n=16$ : $\mathrm{BM} \mathrm{CD} 94^{+} \mathrm{CD} 16^{+}$cells $42.6 \pm 4.4 \%$, spleen $\mathrm{CD} 94^{+} \mathrm{CD} 16^{+}$cells $73.6 \pm 3.1 \%$; NSG, $n=17$ : PB CD94 $4^{+}$CD16 ${ }^{+}$cells $40.7 \pm 4.1 \%$; hIL-7xhIL-15 KI NSG, $n=13: \mathrm{PB} \mathrm{CD} 94^{+} \mathrm{CD} 16^{+}$cells $83.8 \pm 2.3 \% . P<0.001$ in spleen and $\mathrm{PB}$ by two-tailed test; Fig $3 \mathrm{~A}$ and $\mathrm{B}$ absolute numbers of cells are shown in Table S3). In line with phenotypical maturation, human NK cells developing in hIL-7xhIL-15 NSG humanized mice showed higher expression of perforin and granzyme $\mathrm{B}, \mathrm{CD}^{+} 6^{+} \mathrm{NK}$ cell subset (NSG, $n=13$ : perforin ${ }^{+}$cells $25.1 \pm 5.6 \%$, granzyme $\mathrm{B}^{+}$cells $17.8 \pm 4.7 \%$, perforin ${ }^{+}$granzyme $\mathrm{B}^{+}$cells $12.7 \pm 3.9 \%$; hIL-7xhIL-15 KI NSG, $n=10$ : perforin ${ }^{+}$cells $61.4 \pm 4.3 \%$, granzyme $B^{+}$cells $47.0 \pm$ $4.3 \%$, perforin ${ }^{+}$granzyme $B^{+}$cells $39.5 \pm 3.4 \%$. $P<0.001$ in perforin + cells, perforin ${ }^{+}$granzyme $B^{+}$cells, and granzyme $B^{+}$cells by two-tailed $t$ test; Fig 3 C and D, absolute numbers of cells are shown in Table S3). We next assessed functional capacity of human NK cells developing in conventional NSG humanized mice and hIL-7xhIL-15 NSG humanized mice using in vitro cytotoxicity assay. hIL-7xhIL-15 NSG spleen NK cells exhibited cytotoxicity at a similar level compared with human PB NK cells (NSG, $n=3: 5.7 \% \pm 2.2 \%$; hIL-7xhIL-15 KI NSG, $n=8$ : $12.4 \pm 1.8 \%$; human PB, $n=2: 8.1 \pm 1.8 \%$; Fig $3 \mathrm{E})$.

When we analyzed PFA-fixed, paraffin-embedded thin sections of the recipient spleens, we found cells that were specifically stained with anti-hCD56 and NKp46 antibody. Whereas hCD3 ${ }^{+} \mathrm{T}$ cell and hCD19+ B cells appeared to form lymphoid clusters, human NK cells were distributed outside lymphoid clusters, consistent with physiological distribution of human NK cells in human spleen (Witte et al, 1990) (Figs 4 and S4). These findings indicate that hIL-7 and hIL-15 support multiorgan development and maturation of human NK cells in humanized mice.

\section{Maintenance of human NKT cells in hIL-7xhIL-15 KI NSG mice}

Although TCRV $\alpha 24^{+} \mathrm{V} \beta 11^{+} \mathrm{CD} 3^{+} \mathrm{NKT}$ cells were not detected in the BM and spleen of hIL-7xhIL-15 KI NSG humanized mice, we examined whether human IL-7 and human IL-15 maintain human NKT cells for longer term in the BM and lungs. We intravenously injected $2 \times 10^{6}$ cells, human NKT cells, or iPS-NKT cells into NSG mice or hIL-7xhIL15 KI NSG mice. In hIL-7xhIL-15 KI NSG mice, we detected NKT cells or iPS-NKT cells in the BM and lungs at higher frequencies at $14 \mathrm{~d}$ postinjection (NSG, $n=4$ : BM NKT cells $0.000 \%$, lung NKT cells $0.001 \pm$ $0.002 \%$; hIL-7xhIL-15 $n=11 \mathrm{BM}$ NKT cells $0.084 \pm 0.025 \%$, lung NKT cells $0.079 \pm 0.014 \%, P=0.07$ in BM and $P<0.01$ in the lungs by twotailed $t$ test; Fig S5). This finding indicates that hIL-7 and hIL-15 play an important role for the survival of human NKT cells.

\section{Gene expression signatures of human NK cells in hIL-7xhIL-15 KI NSG mice}

Furthermore, we examined gene expression profiles of human NK cells in hIL-7xhIL-15 KI NSG humanized mice by RNA sequencing (Fig 5). We purified hCD $45^{+} \mathrm{CD}_{56}{ }^{+} \mathrm{CD}^{-}$splenic NK cells from hIL-7xhIL-15 KI NSG and conventional NSG humanized mice. In comparison with gene expression signatures of human NK cells in conventional NSG humanized mice and human PBMC-derived NK cells (GSE64655) (Hoek et al, 2015), expression of PRDM1, CCL4L1, CCL4, KIR2DS4, KIR2DL1, KIR2DL3, KIR3DL1, and KIR2DP1 was up-regulated in human NK cells from hIL-7xhIL-15 KI NSG humanized mice. In addition, 
A

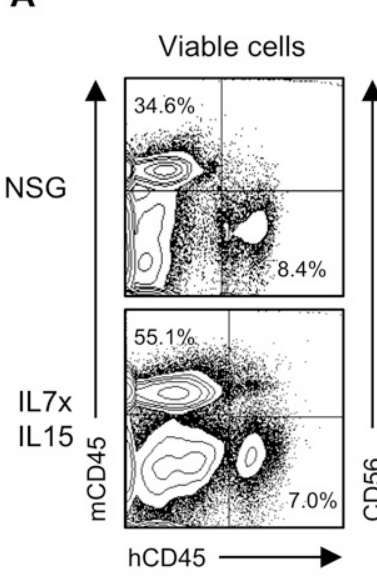

C

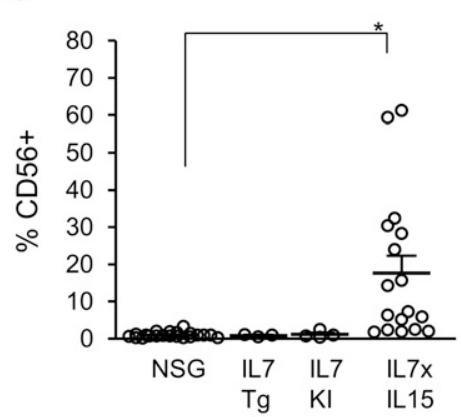

BM hCD45+

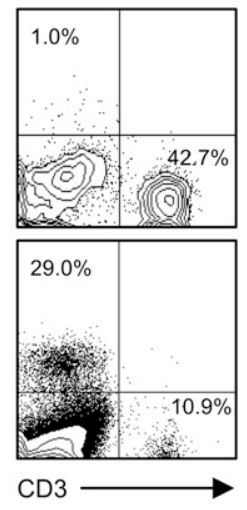

\section{hCD45+}

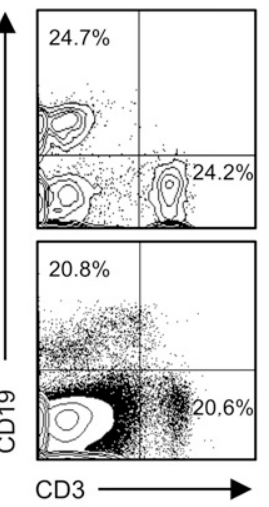

Spleen

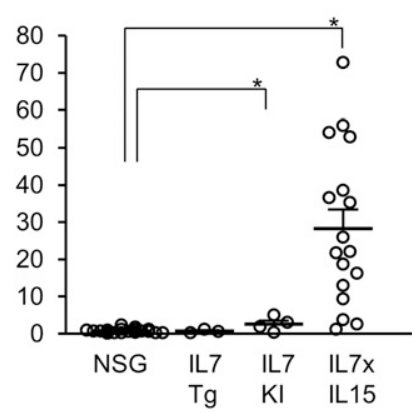

B

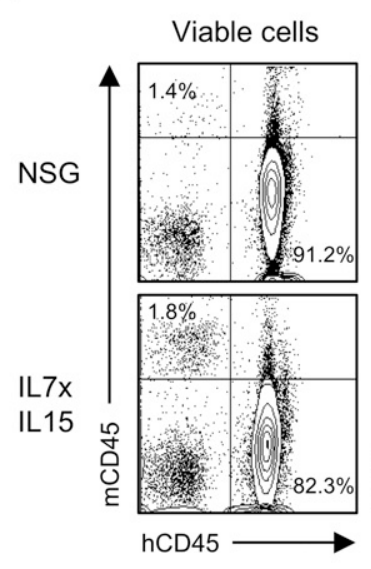

PB

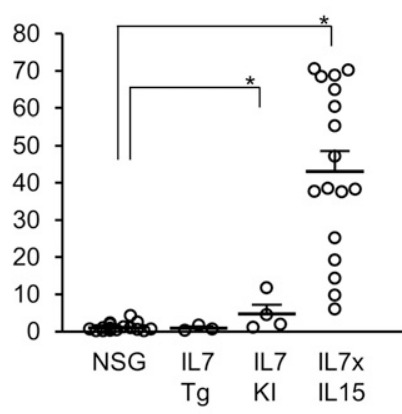

IL7xIL15

CD56+

E

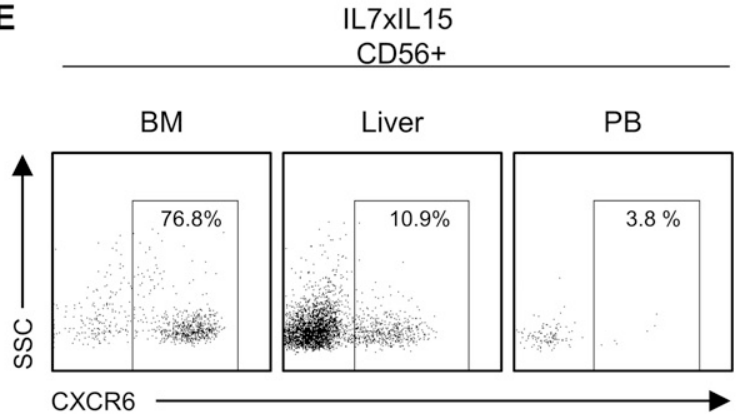

CXCR6

F
Thymus

hCD45+
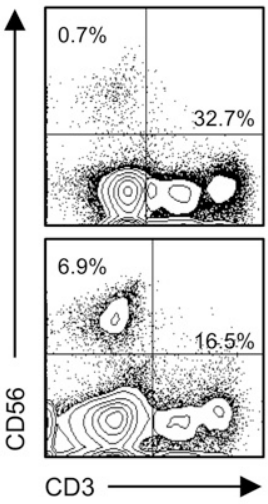

Thymus
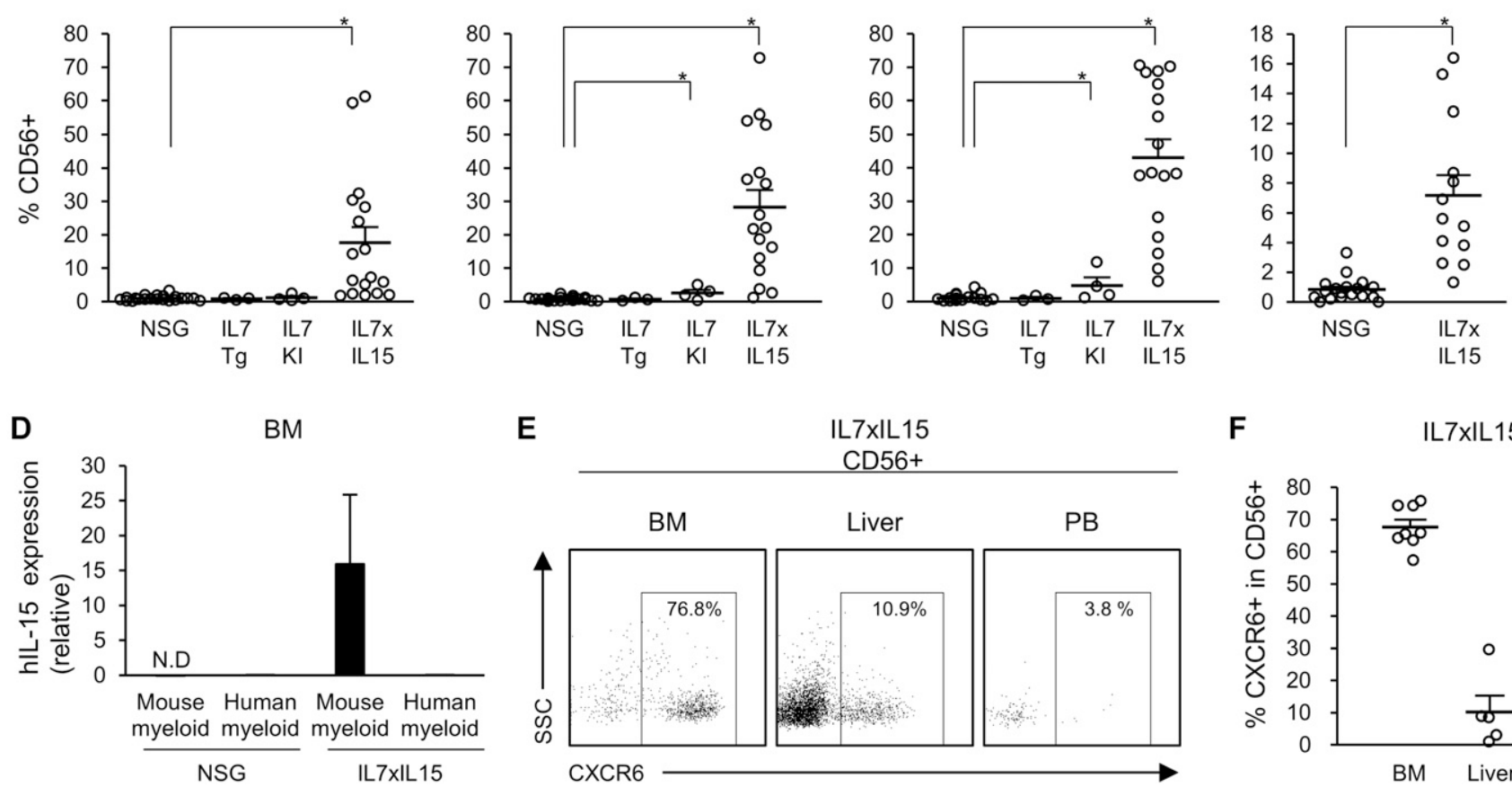

IL7xIL15

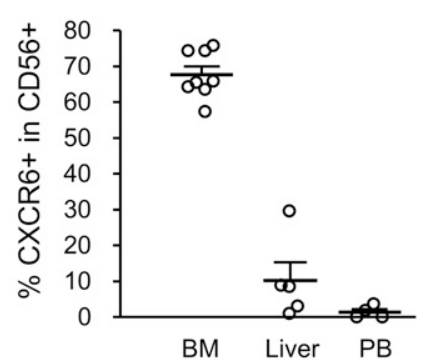

Figure 1. Increased reconstitution of human NK cells in NSG hIL-7xhIL-15 humanized mice.

(A, B) Representative flow cytometry plots of (A) the BM and (B) the thymus of conventional NSG and hIL-7xhIL-15 KI NSG humanized mice (IL7XIL15). (C) Increased frequencies of CD56 ${ }^{+}$NK cells are detected in the BM, spleen, PB, and thymus of NSG hIL-7xhIL-15 KI humanized mice (BM, spleen, and PB: NSG $n=21, I L 7 T G n=3$, IL7KI $n=4$, IL7XIL15 $n=17$,

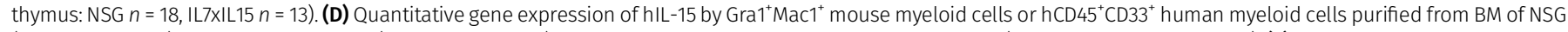
(left two columns) or hIL-7xhIL-15 KI NSG (right two columns) humanized mice are presented relative to $\beta$-actin (NSG $n=3$ and IL7xIL15 $n=3$ ). (E) Representative flow cytometry plots of the BM, liver, and PB of hIL-7xhIL-15 KI NSG humanized mice showing CXCR6 expression among human NK cells. (F) Frequencies of CXCR6 ${ }^{+}$CD56 tissue-resident NK cells in the BM, liver, and PB of NSG hIL-7xhIL-15 KI humanized mice (BM $n=8$, Liver $n=5, P B n=4)$. Error bars represent mean \pm SEM. ${ }^{*} P<0.001$, by two-tailed $t$ test.

cytotoxicity-related genes such as GZMA, GZMB, and PRF1 were upregulated. Similarity of NK cell-associated gene expression between splenic human NK cells in hIL-7xhIL-15 KI NSG humanized mice and human PBMC-derived NK cells suggest that human IL-7 and IL-15 in the splenic microenvironment enhances human NK cell maturation. In contrast, expression of $A H R$ and $I L-7 R$ were down-regulated in NK cells of hIL-7xhIL-15 KI NSG humanized mice and human PBMC compared with those of conventional NSG humanized mice. Among the differentially expressed genes, we analyzed the expression of KIR at the protein level by flow cytometry. Consistent with the transcriptome analysis, expression of KIRs was higher in NK cells developed in hIL-7xhIL-15 KI NSG humanized mice compared with those in conventional NSG humanized mice ( $3.6 \pm 0.8 \%$ in NSG, $n=5$; $12.3 \pm 0.4 \%$ in hIL-7xhIL-15, $P<0.001$ by two-tailed $t$ test; Fig S6).

\section{Discussion}

NK cells were first reported in 1975 (Herberman et al, 1975; Kiessling et al, 1975; Sendo et al, 1975). NK cells exert potent cytotoxic function 
A

Thymus

NSG

CD3+

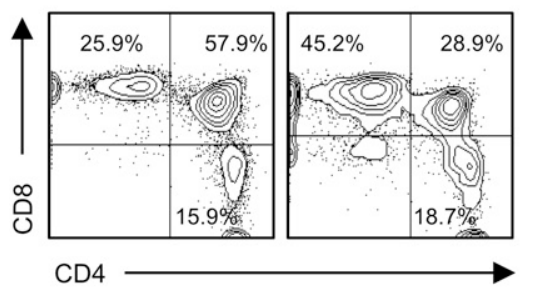

C
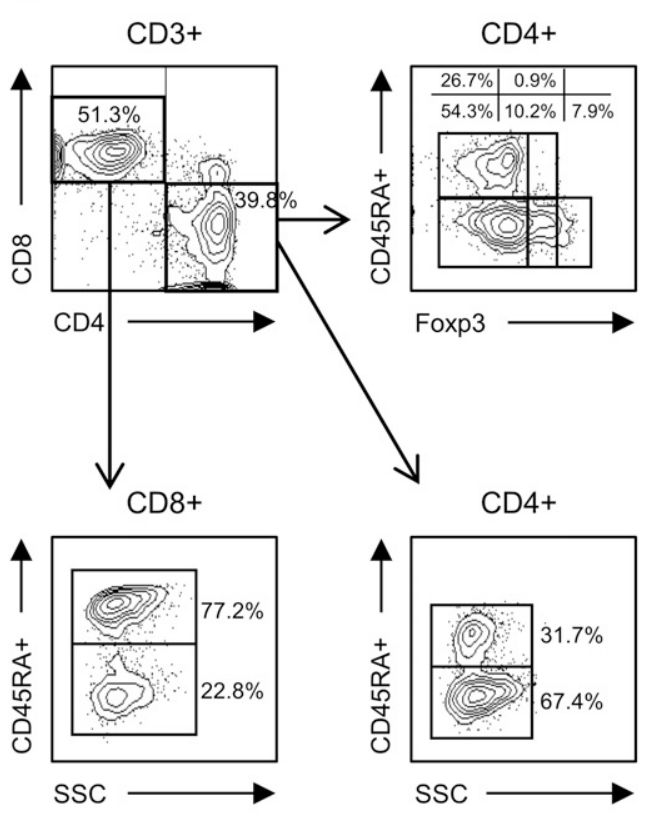

B

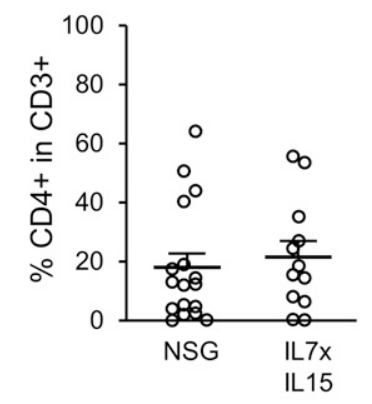

D
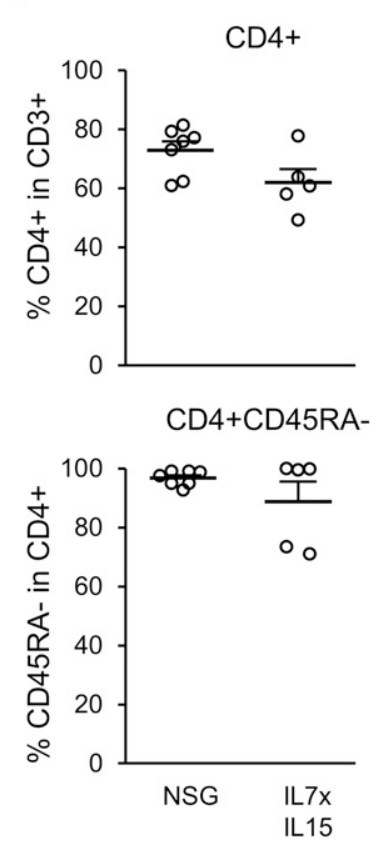

Thymus
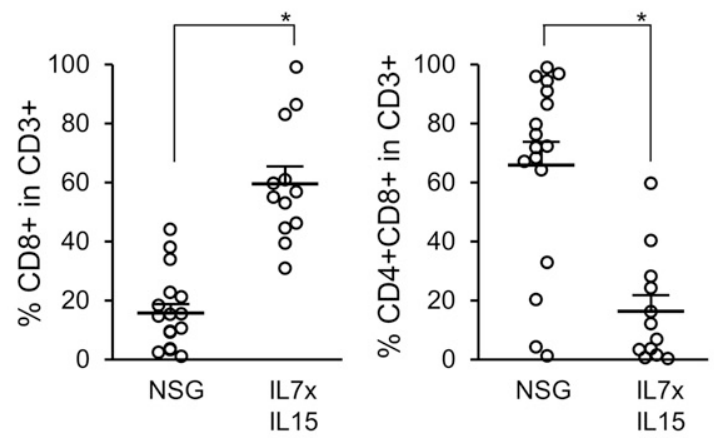

Spleen
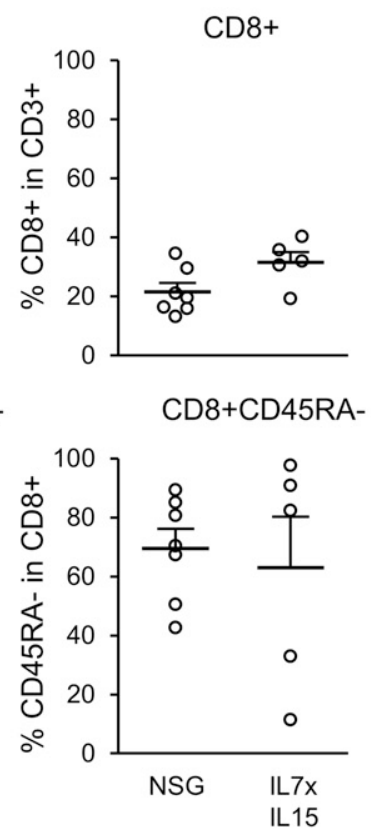

E
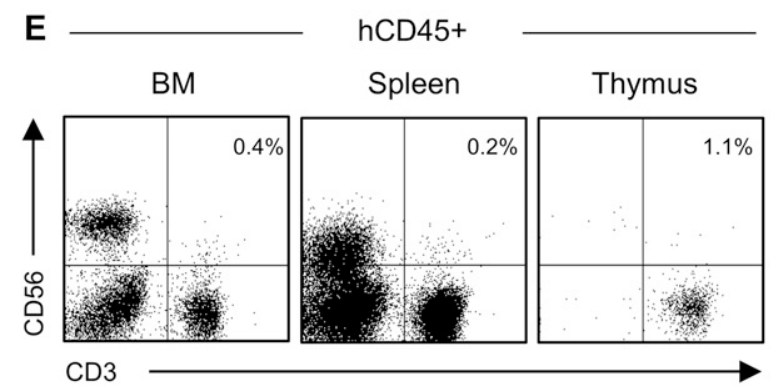

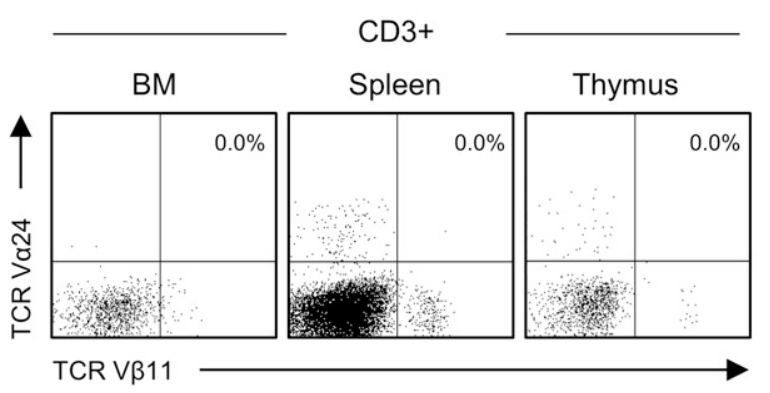

Figure 2. Development of human T-cell subsets in NSG hL-7xhIL-15 humanized mice.

(A) Representative flow cytometry plots of thymic T-cell subset of conventional NSG and hIL-7xhIL-15 KI NSG (IL7xIL15) humanized mice. (B) Frequencies of thymic CD $4^{+} \mathrm{T}$ cells, CD8 ${ }^{+} \mathrm{T}$ cells, and $\mathrm{CD}^{+} \mathrm{CD} 8^{+} \mathrm{T}$ cells in NSG $(n=17)$ and hIL-7xhIL-15 KI NSG humanized mice $(n=12)$. (C) Representative flow cytometry plots of splenic T-cell subsets in a hIL-7xhIL-15 KI NSG humanized mouse. (D) Frequencies of splenic CD4 ${ }^{+} \mathrm{T}$ cells, CD8 ${ }^{+} \mathrm{T}$ cells, CD45RA memory CD $4^{+} \mathrm{T}$ cells, and CD45RA memory CD8 ${ }^{-} \mathrm{T}$ cells in conventional NSG $(n=7)$ and hIL-7xhIL-15 KI NSG $(n=5)$ humanized mice. (E) Representative flow cytometry plots showing a lack of TCR V $\alpha 24^{+}$V $\beta 11^{+}$NKT cells in the BM, spleen, and thymus of a hIL-7xhIL-15 KI NSG humanized mouse. Error bars represent mean \pm SEM ( ${ }^{*} P<0.001$, by two-tailed $t$ test).

against virus-infected cells and MHC-deficient tumor cells. Different from $T$ cells, NK cells are activated when they do not receive inhibitory signals through killer cell immunoglobulin-like receptor
(KIR)-MHC interaction. This mechanism leads to rapid NK cellmediated immune reaction and induction of apoptosis in MHCescaping malignant cells (Anfossi et al, 2006). Like other immune 
A

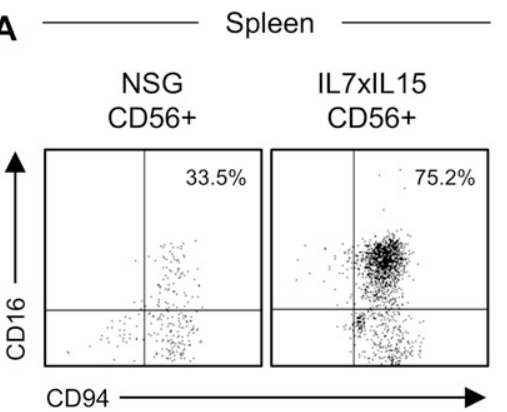

B
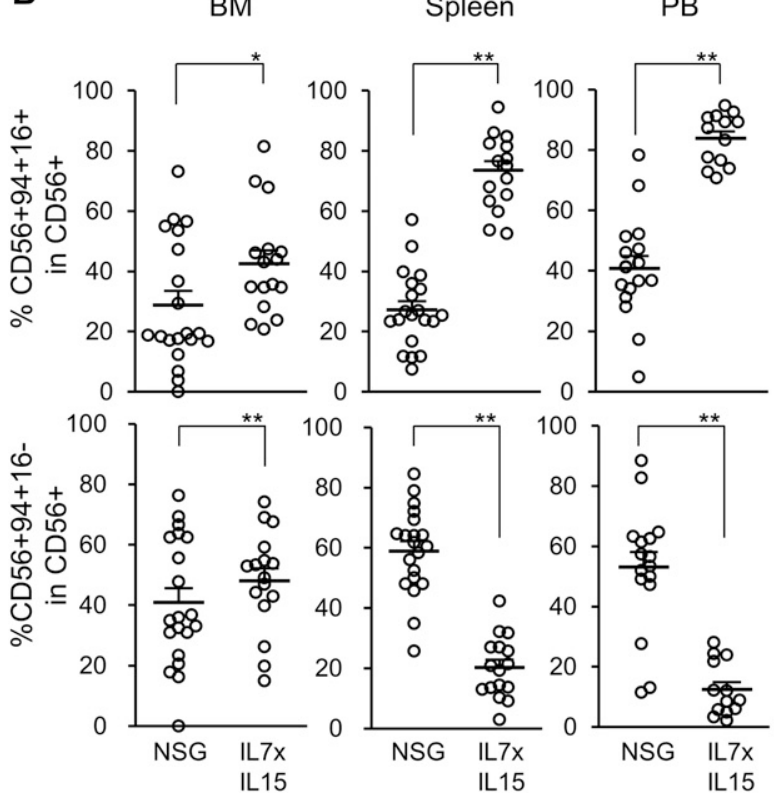

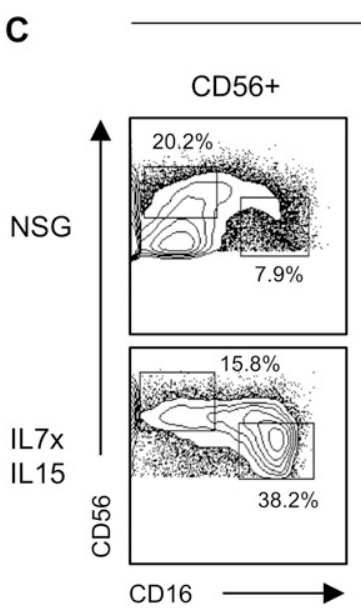

D

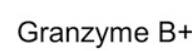

Spleen

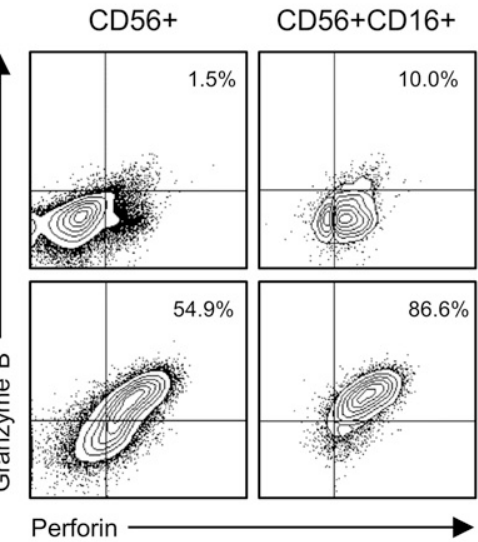

Perforin+

Granzyme B+
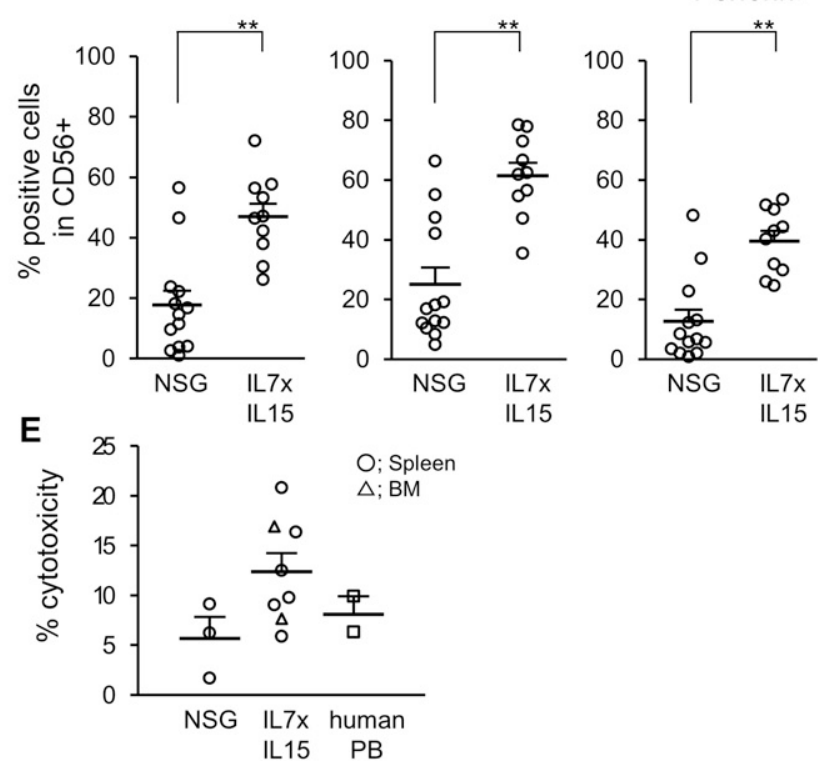

Figure 3. NK cells show a mature phenotype and cytotoxicity in NSG hL-7xhIL-15 humanized mice.

(A) Representative flow cytometry plots of splenic NK cell maturation in conventional NSG and hIL-7xhIL-15 KI NSG humanized mice (IL7xIL15). (B) Increased frequencies of $\mathrm{CD}_{5}{ }^{+} \mathrm{CD} 94^{+} \mathrm{CD} 16^{+}$mature NK cells are detected in the BM, spleen, and PB of hIL-7xhIL-15 KI NSG humanized mice (NSG: BM and spleen $n=20$, PB $n=17$; IL7XIL15: BM and spleen $n=16$, PB $n=13$ ). (C) Representative flow cytometry plots of cytoplasmic expression of granzyme B and perforin in the spleen of NSG and hIL-7xhIL-15 KI NSG humanized mice. (D) Frequencies of granzyme B- and perforin-positive cells among splenic CD56 NK cells in NSG $(n=13)$ and hIL-7xhIL-15 KI NSG ( $n=10)$ humanized mice. (E) In vitro cytotoxicity of human NK cells isolated from spleen of conventional NSG, hIL-7xhIL-15 KI NSG humanized mouse spleen (circles) and BM (triangles), and from normal human PB samples (squares) against K562 are shown (NSG $n=3$; IL7XIL15 $n=7$; normal human PB $n=2$ ). Error bars represent mean $\pm S E M$. ${ }^{\star} P<0.05$, ${ }^{* \star} P<0.001$, by two-tailed $t$ test.

cells, development, maturation, and function of NK cells have been extensively studied using genetically engineered mouse models (Kennedy et al, 2000; Fehniger et al, 2001). Although mouse and human NK cell development share some aspects in their biological function and transcriptome, there are differences between human and mouse NK cells such as the use of Ly 49 receptors by mouse NK cells versus the use of KIR by human NK cells for the recognition of MHC (Colucci et al, 2002). In the present study, we aimed to develop an in vivo model supporting human NK cell maturation and to assess roles of cytokine receptor signaling in human NK cell development. In particular, we aimed to address the following two questions: (1) How do human NK cells develop and distribute in primary and secondary lymphoid organs? (2) How do human NK cells become functionally mature in the microenvironment? To answer these questions, we created NSG mice expressing hIL-7 alone and those expressing both hIL-7 and hIL-15. Unlike NSG mice expressing hIL-7 alone, concurrent expression of hIL-15 resulted in enhanced in vivo human NK development in multiple organs, but not in T cells or NKT cells. Histologically, whereas human T cells and human B cells existed mainly near white pulp-like structures, most human NK cells were located outside the white pulp-like area, consistent with human splenic architecture (Witte et al, 1990). The 


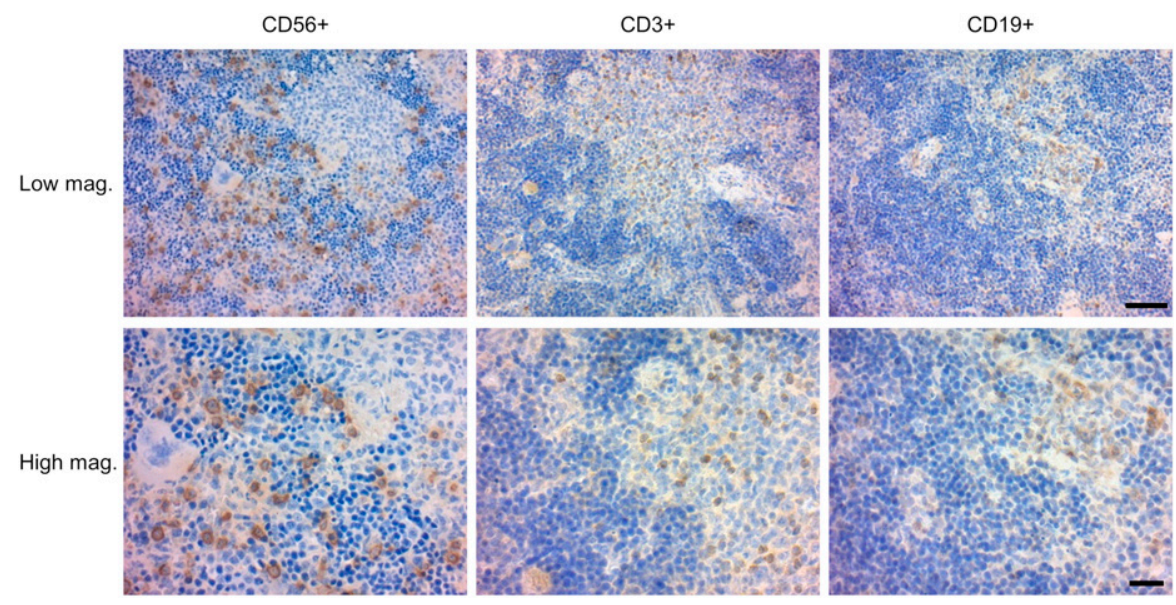

Figure 4. Distribution of splenic $\mathrm{T}$ cells, B cells, and NK cells in NSG hL-7xhIL-15 humanized mice.

Thin sections of a hIL-7xhIL-15 NSG recipient spleen stained with anti-hCD56, anti-CD3 and anti-CD19 antibodies. Low and high magnification images are shown. $\mathrm{hCD} 3^{+} \mathrm{T}$ cell and $\mathrm{hCD} 19^{+} \mathrm{B}$ cells were found within lymphoid clusters, whereas CD56 ${ }^{+}$NK cells are located outside the clusters. Scale bars: low magnification, $50 \mu \mathrm{m}$; high magnification, $20 \mu \mathrm{m}$.

BM is considered as a primary organ for NK cell development and maturation (Huntington et al, 2007). Although emerging evidence has suggested that thymus is also important for NK cell development, it has yet to be understood whether thymus provides essential environmental factors for mouse and human NK cells (Freud et al, 2014; Bjorkstrom et al, 2016). In our xenograft, we found $\mathrm{CD}^{+} 6^{+}$NK cells in both BM and thymus. Thymic NK cells were reported to express IL-7R in mice and human (Vosshenrich et al, 2006). Consistent with the report, we found IL-7R ${ }^{+} C D 56^{+} N K$ cells in the thymus of hIL-7xhIL-15 KI NSG humanized mice (representative flow cytometry plots were shown in Fig S7). This result may suggest that hIL-7 signaling is important for human NK cell development particularly in thymus.

To date, the frequency of $\mathrm{CD} 56^{+} \mathrm{CD} 16^{+}$mature human NK cells in xenotransplantation models have not fully reflected physiological levels. Our report is consistent with previous publications using in vivo administration of hIL-15 or hIL-15-hIL-15R $\alpha$ complex to humanized mice (Huntington et al, 2009; Strowig et al, 2010) and more recently, using hIL-15 expressing BALBC/Rag2KO/IL2rgKO mice assessing differentiation and function of human NK cells in vivo (Herndler-Brandstetter et al, 2017). The new NSG mouse model described in the present work further supports critical roles of IL-15 in human NK cell development. In our new strain, we found $\mathrm{CXCR6}{ }^{+} \mathrm{CD}^{+} 6^{+}$tissue-resident NK cells in the BM and liver. Because tissue-resident NK cells and circulating NK cells are different in cytotoxicity or cytokine production (Melsen et al, 2018), hIL-7xhIL-15 KI NSG humanized mice could be useful for studying the two distinct subsets of human NK cells. In addition to flow cytometric analysis of engrafted human NK cells, we performed transcriptome analysis by RNA sequencing. We found that the gene expression signature of human NK cells in hIL-7xhIL-15 KI NSG humanized mice was more similar to those in human PB as compared with human NK cells in conventional NSG humanized mice. It would be notable that maturation or cytotoxic markers such as KIRs, chemokine ligands (CCL4L1 and CCL4), cytotoxicityrelated genes (GZMA and GZMB), as well as PRDM1 were upregulated in the NK cells in hIL-7xhIL-15 KI NSG humanized mice because all these genes were known as NK-specific functional molecules (Fehniger et al, 1999; Parham, 2005; Yawata et al, 2006; Smith et al, 2010), and that the new humanized mice could be a better in vivo model for assessing interaction between NK cells and diseased cells.

We also assessed potential development and survival of human NKT cells in the NSG mice expressing hIL-7 and hIL-15. In the mice engrafted with human CB HSCS, we did not see differentiation of human NKT cells in organs such as the BM, spleen, and lungs, suggesting that these two cytokines are not sufficient to support human NKT cell development. On the other hand, with in vivo transfer of human NKT cells into hIL-7xhIL-15 KI NSG mice, the injected human NKT cells were detected at higher frequencies in multiple organs as compared with NSG mice. Because NKT cells are known to activate NK cells in vivo, the model would be useful to analyze activation of human NK cells with intravenous injection of human NKT cells (Carnaud et al, 1999; Fujii et al, 2010; Yamada et al, 2016).

Together, expression of hIL-7 and hIL-15 in the NSG humanized mice resulted in efficient development of human NK cells in multiple organs in the presence of multiple human immune subsets, and the human NK cells undergo physiological maturation process and exhibit cytotoxicity. The new humanized mouse model with hIL-7 and hIL-15 expression could be used as a valuable tool for examining in vivo biology of human NK cells and for in vivo testing of NK cell-mediated cytotoxicity against cancer.

\section{Materials and Methods}

\section{Human samples}

Human CB cells were obtained from Tokai Cord Blood Bank and Chubu Cord Blood Bank under written informed consent. All experiments were authorized by the institutional review boards at RIKEN.

\section{Mice}

NOD.Cg-Prkdc scid $/ 12 \mathrm{rg}^{\text {tmiWjl }} / \mathrm{SzJ}$ (NSG) mice were raised from a breeding colony maintained at RIKEN. To generate human IL-7 transgenic mice (NSG.Cg-C57BL/6-Tg(Hu-IL7)1Rk) (hIL-7 TG), the 
A

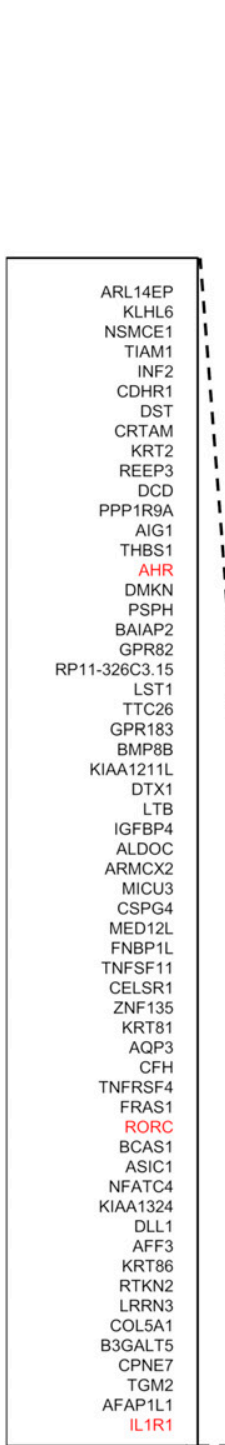

NK cells in

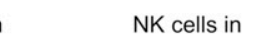
hIL7xhIL15 KI

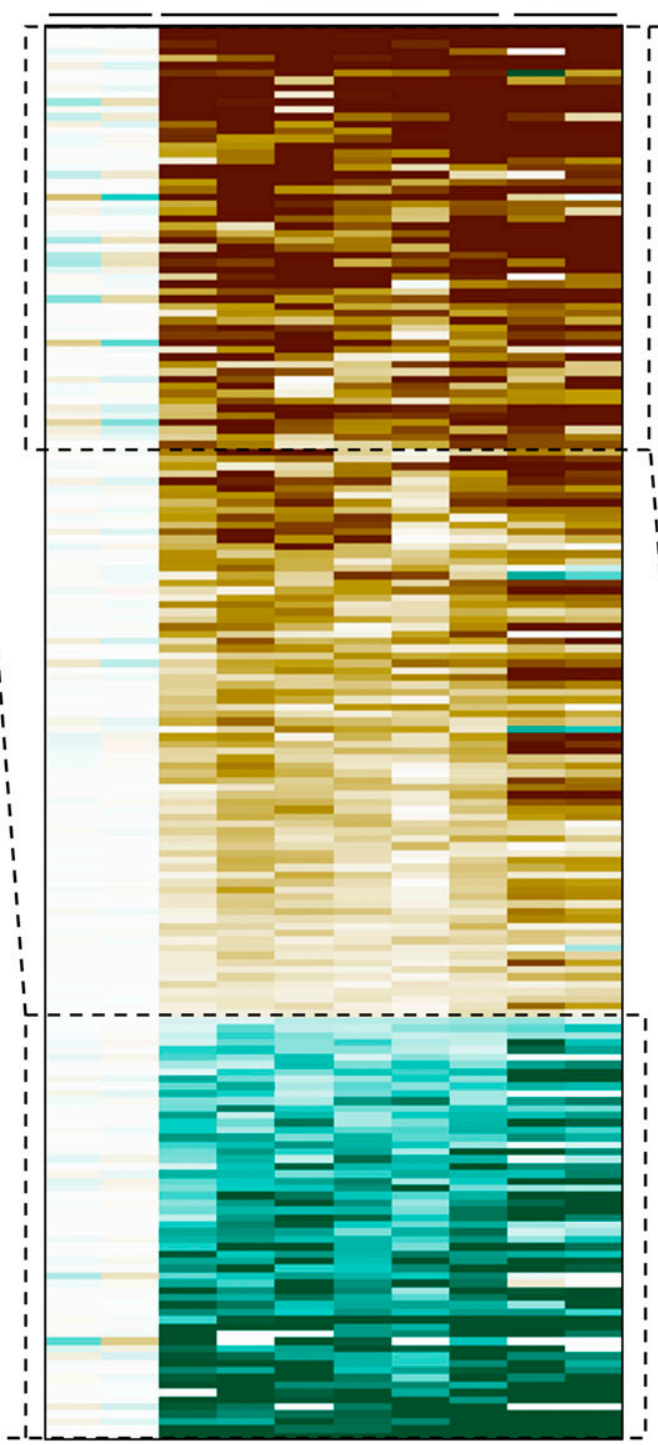

B
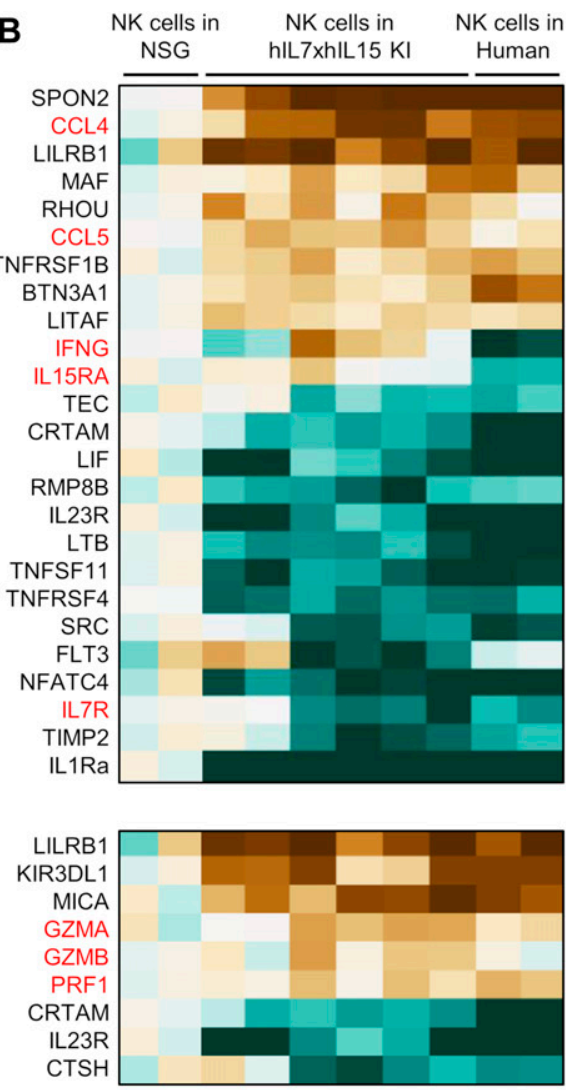

Figure 5. Gene expression signature of NK cells in NSG hL-7xhIL-15 humanized mice.

RNA sequencing was performed using RNA extracted from hCD56+ splenic NK cells of conventional NSG (NSG, $n=2$ ) and hIL-7xhIL-15 KI NSG (hIL7xhIL-15 KI NSG, $n=6$ ) humanized mice. (A) Differentially expressing genes are shown. Gene expression profiles of human NK cells of humanized mice were compared with those from NK cells recovered from human PBMCS. (B) Expression of genes related to cytokine and cytotoxicity are shown.

pBACe3.6 vector containing the human IL-7 genomic region (Fig S8A; BAC clone RPCl11.C-19N15 [Thermo Fisher scientific]) was microinjected into the pronucleus of fertilized $\mathrm{C} 57 \mathrm{BL} / 6 \mathrm{~J}$ (B6/J) mouse embryos. To generate human IL-7 knockin mice (NSG.CG-STOCK-

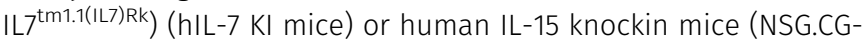
STOCK-IL15 ${ }^{\text {tm1.1(IL15)Rk}) ~(h I L-15 ~ K I ~ m i c e), ~ B 6 / J ~ × ~ 129 / S v ~ h y b r i d ~ E S ~ c e l l s ~}$ were transfected with targeting vector containing human IL-7 or human IL-15 CDNA by electroporation and cultured for 7-10 $d$ to select homologous recombinants. Then, correctly targeted ES cell clones were aggregated with BDF2 morula to generate chimeric mice. Male chimeras were mated with B6/J females, and heterozygous offsprings were further mated with B6; SJL-Tg (ACTFLPe) 9205Dym/J mice to remove the PGK-Neo cassette (Fig S8A). hIL-7 TG mice, hIL-7 KI mice, and hIL-15 KI mice were backcrossed more than five generations onto the NSG mice. Backcrossing was performed by means of natural mating, in vitro fertilization, or round spermatid injection. Backcrossed mice at each generation were selected using a marker-assisted selection protocol for further backcrossing. Human IL-7 and human IL-15 double knockin NSG mice (hIL-7xhIL-15 KI NSG) were generated by crossing hIL-7 KI NSG mice and hIL-15 KI NSG mice. B6/J and BDF1 mice were purchased from CLEA Japan. B6; SJL-Tg (ACTFLPe)9205Dym/J mice were purchased from the Jackson Laboratory.

All mice were bred and maintained under specific pathogen free conditions at the animal facility of RIKEN Integrative Medical Sciences. All animal experiments were performed in accordance with 
guidelines and approved by the Institutional Animal Care and Use Committee of RIKEN.

\section{Genotyping of NSG mice}

hIL-7 TG mice, hIL-7 KI mice, and hIL-15 KI mice were genotyped by PCR (Bio-Rad, Takara Bio, or BM Equipment). Primer information used for this genotyping is shown in Fig S8B. The microsatellite markers used for marker-assisted selection protocol were selected based on sequence length polymorphisms between B6 mice and NOD mice (according to Mouse Microsatellite Date Base of Japan [MMDBJ]; https://shigen.nig.ac.jp/mouse/mmdbj/top.jsp, Table S5). All primers were purchased from Life Technologies Japan.

\section{Transplantation}

Antihuman CD34 immune-magnetic beads (130-046-703; Miltenyi Biotec) were used to enrich human $\mathrm{CD}_{3} 4^{+}$cells from $\mathrm{CB}$ samples. Enriched human $\mathrm{CD} 34^{+}$cells were sorted for 7-AAD- $\mathrm{Lin}^{-} \mathrm{hCD} 45^{+} \mathrm{CD} 34^{+}$

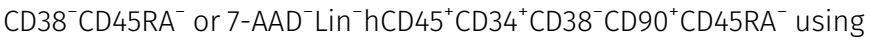
FACSAria or FACSAria III (BD Biosciences). NSG, hIL-7 Tg NSG, hIL-7 KI NSG, and hIL-7xhIL-15 KI NSG newborn mice received 150 cGy total body irradiation using a ${ }^{137} \mathrm{Cs}$-source irradiator, followed by intravenous injection of $2.5 \times 10^{3}$ to $2.6 \times 10^{4}$ sorted HSCs. Recipient PB samples were evaluated for human hematopoietic engraftment every 4 wk starting at 5-6 wk after transplantation. Recipients with confirmed human hematopoietic engraftment at 10-24 wk after transplantation were euthanized and analyzed.

\section{Flow cytometric analysis}

Cells obtained from PB and various organs were stained with mAbs and analyzed using FACSAria, FACSAria III, or FACSCanto II (BD Biosciences). The following mAbs were used for flow cytometry: anti-hCD3-BV421 (UCHT1), -allophycocyanin (APC) (HIT3a), and -BV786 (SK7), anti-hCD4-phycoerhthrin (PE)-Cy7 (SK3), anti-hCD8APC-Cy7 (SK1), anti-hCD10-BV421 (HI10a), anti-hCD16-PE-Cy7 (3G8), and Pacific blue (3G8), anti-hCD19-PE-Cy7 (SJ25C1) and -BV786 (SJ25C1), anti-hCD20-APC (L27), anti-hCD33-PE (WM53), anti-hCD34PE-Cy7 (8G12), anti-hCD38-APC (HB7), anti-hCD45-APC (HI30), -BV510 (HI30), and -APC-H7 (2D1), anti-hCD45RA-FITC (HI100), anti-hCD56FITC (NCAM16.2), -BV421 (NCAM16.2), and -BV711 (NCAM16.2), antihCD90-FITC (5E10), anti-hIgD-PE (IA6-2), anti-hIgM-FITC (G20-127), anti-mCD45-APC-Cy7 (30-F11) and -BV510 (30-F11), anti-mCD11b-BV421 (Mac1) (M1/70), and Ly-6G/6C-FITC (Gra1) (RB6-8C5) (all from BD Biosciences), anti-hTCR-V $\alpha 24-P E$ (C15), anti-hTCR-V $\beta 11-A P C$ (C21), anti-hCD127 (IL-7Ra) (R34.34) and anti-hCD158a,h (KIR2DL1/ 2DS1) (EB6B) (all from Beckman Coulter), anti-hCD94-PE (HP-3D9; eBioscience), and anti-hCD186-APC (CXCR6) (K041E5; BioLegend).

For analysis of regulatory $T$ cells, cells stained with mAbs for surface antigens were fixed and permeabilized using FoxP3/Transcription Factor Staining Buffer Set (eBioscience). Permeabilized cells were stained with anti-hFoxp3-APC (clone PCH101; eBioscience) and analyzed using FACSCanto II (BD Biosciences). To analyze the expression of intracellular granzyme $B$ and perforin, cells stained with mAbs for surface antigens were fixed and permeabilized using BD Cytofix/Cytoperm Kit (BD Biosciences). Permeabilized cells were stained with anti-human granzyme B-FITC (GB11; BD Biosciences) and anti-human perforin-PE ( $\delta G 9 ;$ BD Biosciences) and analyzed using FACSCanto II (BD Biosciences).

\section{Measurement of plasma cytokine levels}

To measure concentrations of cytokines in recipient plasma samples, PB samples were obtained from NSG, hIL-7 Tg NSG, hIL-7 KI NSG, and hIL-7xhIL-15 KI NSG mice using heparinized capillary tubes (Drummond Scientific Company). Plasma human IL-7 concentration was measured by ELISA (R\&D Systems). Plasma human IL-15 concentration was measured by Bio-Plex Systems (Bio-Rad).

\section{Cytotoxicity analysis}

Human NK cells from recipient mice and human PBMCs were enriched using NK cell isolation kit (Miltenyi Biotec). Cytotoxicity of NK cells against $\mathrm{K} 562$ cells were measured using LDH cytotoxicity detection kit (MK401, TaKaRa) (Korzeniewski \& Callewaert, 1983; Fernandez et al, 1986; Bae \& Lee, 2014). In short, 2-5 × $10^{4}$ human NK cells were cultured with K562 at a ratio of 10:1 for $4 \mathrm{~h}$ followed by measurement of LDH in the culture supernatant by ELISA at an absorbance of $490 \mathrm{~nm}$ and cytotoxicity was calculated as follows: cytotoxicity (\%) = [(absorbance of NK and K562 cell co-culture) - (absorbance of NK cells alone) - (absorbance of $\mathrm{K} 562$ alone ) + (absorbance of medium alone)]/[(absorbance of K562 in 10\% Triton X) - (absorbance of K562 alone)] $\times 100$.

\section{Immunohistochemistry}

Tissues were fixed with $4 \%$ paraformaldehyde, dehydrated, embedded in paraffin, and cut into $3-\mu \mathrm{m}$ sections. Following deparaffinization and rehydration, antigen retrieval was performed using $0.1 \%$ calcium chloride solution (for CD56 and NCR1 [Nkp46] labeling) or Retrievagen B solution (for CD3 or CD19 labeling) ( $\mathrm{pH}$ 9.5; $\mathrm{BD}$ Biosciences). Antigen retrieval was performed for $20 \mathrm{~min}$ at $90^{\circ} \mathrm{C}$ for CD56 and Nkp46 labeling and at $94^{\circ} \mathrm{C}$ for CD3 and CD19 labeling according to the manufacturer's protocols. Endogenous peroxidase activity and nonspecific binding were blocked with hydrogen peroxide solution and $2.5 \%$ normal horse serum, respectively. Primary antibodies used in the study were mouse antihuman CD56 (MOC-31; Abcam), rabbit antihuman Nkp46 (ab199128; Abcam), mouse antihuman CD3 (PS1; Abcam), and rabbit antihuman CD19 (EPR5906; Abcam). ImmPRESS MP-7500 was used as the secondary antibody (VECTOR). 3,3'-diaminobenzidine (DAB; SK-4100, VECTOR) and hematoxylin were used as the chromogen and counterstain, respectively. After mounting with cover glass, images were obtained using Axiovert 200 (Carl Zeiss).

\section{NKT cell injection}

Human NKT cells and human iPS-NKT cells were prepared using a previously established method (Yamada et al, 2017). $2.0 \times 10^{6} \mathrm{NKT}$ cells were intravenously injected into NSG mice and hIL-7xhIL-15 KI NSG mice. At $14 \mathrm{~d}$ postinjection, the recipients were euthanized and analyzed for the presence of human NKT cells in the BM and lungs. 


\section{RNA extraction and qPCR}

BM cells of NSG and hIL7xhIL-15 KI NSG humanized mice were labeled with anti-mGra1-FITC, anti-hCD33-PE, anti-mCD45-APC-Cy7, anti-Mac1-BV421, and anti-hCD45-BV510 to purify Mac1 ${ }^{+}$Gra1 ${ }^{+}$mouse myeloid cells and hCD $45^{+} \mathrm{CD} 33^{+}$human myeloid cells using FACSAria III (BD Biosciences). Total RNA was extracted using Trizol reagent (Invitrogen). Total RNA was quantified using a fluorimetric RiboGreen assay, and RNA quality was assessed using Bioanalyzer (Agilent Technologies). Extracted RNA was converted into cDNA using Superscript III reverse transcriptase (Invitrogen). Real-time PCR reactions were performed using Platinum Quantitative PCR SuperMix-UDG (Invitrogen) on a LightCycler 480 real-time PCR system (Roche) using the following primers:

IL-15-Forward 5'-ACAGAAGCCAACTGGGTGAA-3';

IL-15-Reverse 5'-TCCAAGAGAAAGCACTTCATTGC-3';

IL-15-Probe 5' -(6FAM)CTTTGCAACTGGGGTGAACATCACTTTCCG (TAM)-3'.

Relative expression levels were calculated for each gene using ACTB for normalization.

\section{RNA sequencing analysis}

Total RNA extracted from splenic CD56 ${ }^{+}$NK cells in NSG recipient, and hIL-7xhIL-15 KI NSG recipient was prepared for RNA sequencing using NEBNext Ultra RNA Library Prep kit for Illumina (catalog number E7530; New England Biolabs). Final library size distribution was validated using Bioanalyzer and quantified using quantitative PCR. The DNA libraries were hybridized to a flow cell, amplified on the Illumina cBot, and subsequently run on the Hiseq 2500 (Illumina, on a 50-base single-end read mode). Raw data are deposited at the National Bioscience Database Center (accession number: hum0171). The sequence reads were mapped to the human genome (NCBI version 19) using TopHat2 version 2.0.8 and botwie2 version 2.1.0 with default parameters, and gene annotation was provided by NCBI RefSeq. The transcript abundances were estimated using Cufflinks (version 2.1.1). Cufflinks was run with the same reference annotation with TopHat2 to generate FPKM (fragments per kilobase per million mapped reads) values for known gene models.

\section{Quantification and statistical analysis}

Quantification and statistical analysis were performed using excel. The numerical data are presented as means \pm SEM. The differences were determined by two-tailed $t$ tests, and $P$ value $<0.05$ was considered statistically significant.

\section{Supplementary Information}

Supplementary Information is available at https://doi.org/10.26508/lsa. 201800195.

\section{Acknowledgements}

We thank Chubu Cord Blood Bank for providing us with human CB and Juri Shioya for measuring cytokine concentration in the recipient plasma. This study was supported by MEXT KAKENHI grant no. JP24111009 (to F Ishikawa), the Basic Science and Platform Technology Program for Innovative Biological Medicine from Japan Agency for Medical Research and Development (to F Ishikawa), the Research Center Network for Realization of Regenerative Medicine from Japan Agency for Medical Research and Development (to $\mathrm{H}$ Koseki), and CREST, Japan Science Technology Agency (to H Koseki).

\section{Author Contributions}

M Matsuda: data curation, formal analysis, methodology, and writing-original draft, review, and editing.

R Ono: formal analysis, validation, investigation, and methodology.

T lyoda: investigation and methodology.

T Endo: data curation, validation, and investigation.

Y Saito: conceptualization, supervision, project administration, and writing-original draft, review, and editing.

A Kaneko: data curation and formal analysis.

K Shimizu: formal analysis, validation, and investigation.

D Yamada: formal analysis, validation, investigation, and methodology.

N Ogonuki: formal analysis, investigation, and methodology.

$T$ Watanabe: data curation, formal analysis, and validation.

M Nakayama: formal analysis, supervision, validation, and investigation.

Y Koseki: formal analysis, supervision, and investigation.

F Kezuka-Shiotani: formal analysis and investigation.

T Hasegawa: resources, supervision, investigation, and project administration.

A Ogura: conceptualization, resources, supervision, investigation, and methodology.

LD Shultz: conceptualization, supervision, and writing-original draft and project administration.

O Ohara: conceptualization, supervision, project administration, and writing-original draft, review, and editing.

M Taniguchi: conceptualization and supervision.

$\mathrm{H}$ Koseki: conceptualization, supervision, funding acquisition, and project administration.

S Fujii: conceptualization and supervision.

F Ishikawa: conceptualization, supervision, funding acquisition, investigation, project administration, and writing-original draft.

\section{Conflict of Interest Statement}

The authors declare that they have no conflict of interest.

\section{References}

Ali AK, Nandagopal N, Lee SH (2015) IL-15-PI3K-AKT-mTOR: A critical pathway in the Life journey of natural killer cells. Front Immunol 6: 355. doi:10.3389/fimmu.2015.00355

Andre MC, Erbacher A, Gille C, Schmauke V, Goecke B, Hohberger A, Mang P, Wilhelm A, Mueller I, Herr W, et al (2010) Long-term human CD34+ stem cell-engrafted nonobese diabetic/SCID/IL-2R gamma(null) mice show impaired CD8+ T cell maintenance and a functional arrest of immature NK cells. J Immunol 185: 2710-2720. doi:10.4049/jimmunol.1000583

Anfossi N, Andre P, Guia S, Falk CS, Roetynck S, Stewart CA, Breso V, Frassati C, Reviron D, Middleton D, et al (2006) Human NK cell education by 
inhibitory receptors for MHC class I. Immunity 25: 331-342. doi:10.1016/ j.immuni.2006.06.013

Bae DS, Lee JK (2014) Development of NK cell expansion methods using feeder cells from human myelogenous leukemia cell line. Blood Res 49: 154-161. doi:10.5045/br.2014.49.3.154

Bjorkstrom NK, Ljunggren HG, Michaelsson J (2016) Emerging insights into natural killer cells in human peripheral tissues. Nat Rev Immunol 16: 310-320. doi:10.1038/nri.2016.34

Carnaud C, Lee D, Donnars O, Park SH, Beavis A, Koezuka Y, Bendelac A (1999) Cutting edge: Cross-talk between cells of the innate immune system: NKT cells rapidly activate NK cells. J Immunol 163: 4647-4650.

Colucci F, Di Santo JP, Leibson PJ (2002) Natural killer cell activation in mice and men: Different triggers for similar weapons? Nat Immunol 3: 807-813. doi:10.1038/ni0902-807

Cui G, Hara T, Simmons S, Wagatsuma K, Abe A, Miyachi H, Kitano S, Ishii M, Tani-ichi S, Ikuta K (2014) Characterization of the IL-15 niche in primary and secondary lymphoid organs in vivo. Proc Natl Acad Sci U S A 111: 1915-1920. doi:10.1073/pnas.1318281111

Fehniger TA, Shah MH, Turner MJ, VanDeusen JB, Whitman SP, Cooper MA, Suzuki K, Wechser M, Goodsaid F, Caligiuri MA (1999) Differential cytokine and chemokine gene expression by human NK cells following activation with IL-18 or IL-15 in combination with IL-12: Implications for the innate immune response. J Immunol 162: 4511-4520.

Fehniger TA, Suzuki K, Ponnappan A, VanDeusen JB, Cooper MA, Florea SM, Freud AG, Robinson ML, Durbin J, Caligiuri MA (2001) Fatal leukemia in interleukin 15 transgenic mice follows early expansions in natural killer and memory phenotype CD8+ T cells. J Exp Med 193: 219-231. doi:10.1084/jem.193.2.219

Fernandez LA, Pope B, Lee C, Zayed E (1986) Aggressive natural killer cell leukemia in an adult with establishment of an NK cell line. Blood 67: 925-930.

Freud AG, Yu J, Caligiuri MA (2014) Human natural killer cell development in secondary lymphoid tissues. Semin Immunol 26:132-137. doi:10.1016/j. smim.2014.02.008

Fujii S, Motohashi S, Shimizu K, Nakayama T, Yoshiga Y, Taniguchi M (2010) Adjuvant activity mediated by iNKT cells. Semin Immunol 22: 97-102. doi:10.1016/j.smim.2009.10.002

Gillgrass A, Gill N, Babian A, Ashkar AA (2014) The absence or overexpression of IL-15 drastically alters breast cancer metastasis via effects on NK cells, CD4 T cells, and macrophages. J Immunol 193: 6184-6191. doi:10.4049/jimmunol.1303175

Herberman RB, Nunn ME, Lavrin DH (1975) Natural cytotoxic reactivity of mouse lymphoid cells against syngeneic acid allogeneic tumors. I. Distribution of reactivity and specificity. Int J Cancer 16: 216-229. doi:10.1002/ijc.2910160204

Herndler-Brandstetter D, Shan L, Yao Y, Stecher C, Plajer V, Lietzenmayer M, Strowig T, de Zoete MR, Palm NW, Chen J, et al (2017) Humanized mouse model supports development, function, and tissue residency of human natural killer cells. Proc Natl Acad Sci U S A 114: E9626-E9634. doi:10.1073/pnas.1705301114

Hoek KL, Samir P, Howard LM, Niu X, Prasad N, Galassie A, Liu Q, Allos TM, Floyd KA, Guo Y, et al (2015) A cell-based systems biology assessment of human blood to monitor immune responses after influenza vaccination. PLoS One 10: e0118528. doi:10.1371/journal.pone.0118528

Huntington ND, Legrand N, Alves NL, Jaron B, Weijer K, Plet A, Corcuff E, Mortier E, Jacques $\mathrm{Y}$, Spits $\mathrm{H}$, et al (2009) IL-15 trans-presentation promotes human NK cell development and differentiation in vivo. J Exp Med 206: 25-34. doi:10.1084/jem.20082013

Huntington ND, Vosshenrich CA, Di Santo JP (2007) Developmental pathways that generate natural-killer-cell diversity in mice and humans. Nat Rev Immunol 7: 703-714. doi:10.1038/nri2154
Ishikawa F, Yasukawa M, Lyons B, Yoshida S, Miyamoto T, Yoshimoto G, Watanabe T, Akashi K, Shultz LD, Harada M (2005) Development of functional human blood and immune systems in NOD/SCID/IL2 receptor \{gamma\} chain(null) mice. Blood 106: 1565-1573. doi:10.1182/ blood-2005-02-0516

Kennedy MK, Glaccum M, Brown SN, Butz EA, Viney JL, Embers M, Matsuki N Charrier K, Sedger L, Willis CR, et al (2000) Reversible defects in natural killer and memory CD8 T cell lineages in interleukin 15-deficient mice. J Exp Med 191: 771-780. doi:10.1084/jem.191.5.771

Kiessling R, Klein E, Wigzell H (1975) "Natural” killer cells in the mouse. I. Cytotoxic cells with specificity for mouse Moloney leukemia cells. Specificity and distribution according to genotype. Eur J Immunol 5: 112-117. doi:10.1002/ eji.1830050208

Korzeniewski C, Callewaert DM (1983) An enzyme-release assay for natural cytotoxicity. J Immunol Methods 64:313-320. doi:10.1016/0022-1759(83) 90438-6

Lodolce JP, Boone DL, Chai S, Swain RE, Dassopoulos T, Trettin S, Ma A (1998) IL-15 receptor maintains lymphoid homeostasis by supporting lymphocyte homing and proliferation. Immunity 9: 669-676. doi:10.1016/s1074-7613(00)80664-0

Mackall CL, Fry TJ, Gress RE (2011) Harnessing the biology of IL-7 for therapeutic application. Nat Rev Immunol 11: 330-342. doi:10.1038/nri2970

Melsen JE, Lugthart G, Vervat C, Kielbasa SM, van der Zeeuw SAJ, Buermans HPJ, van Ostaijen-Ten Dam MM, Lankester AC, Schilham MW (2018) Human bone marrow-resident natural killer cells have a unique transcriptional profile and resemble resident memory CD8(+) T cells. Front Immunol 9: 1829. doi:10.3389/fimmu.2018.01829

Mestas J, Hughes CC (2004) Of mice and not men: Differences between mouse and human immunology. J Immunol 172: 2731-2738. doi:10.4049/ jimmunol.172.5.2731

Moro K, Yamada T, Tanabe M, Takeuchi T, Ikawa T, Kawamoto H, Furusawa J, Ohtani M, Fujii H, Koyasu S (2010) Innate production of $\mathrm{T}(\mathrm{H}) 2$ cytokines by adipose tissue-associated c-Kit(+)Sca-1(+) lymphoid cells. Nature 463: 540-544. doi:10.1038/nature08636

Parham P (2005) MHC class I molecules and KIRs in human history, health and survival. Nat Rev Immunol 5: 201-214. doi:10.1038/nri1570

Peschon JJ, Morrissey PJ, Grabstein KH, Ramsdell FJ, Maraskovsky E, Gliniak BC Park LS, Ziegler SF, Williams DE, Ware CB, et al (1994) Early lymphocyte expansion is severely impaired in interleukin 7 receptor-deficient mice. J Exp Med 180: 1955-1960. doi:10.1084/jem.180.5.1955

Puel A, Ziegler SF, Buckley RH, Leonard WJ (1998) Defective IL7R expression in $\mathrm{T}(-) \mathrm{B}(+) \mathrm{NK}(+)$ severe combined immunodeficiency. Nat Genet 20: 394-397. doi:10.1038/3877

Sendo F, Aoki T, Boyse EA, Buafo CK (1975) Natural occurrence of lymphocytes showing cytotoxic activity to BALB/C radiationinduced leukemia RL male 1 cells. J Natl Cancer Inst 55: 603-609. doi:10.1093/jnci/55.3.603

Shultz LD, Lyons BL, Burzenski LM, Gott B, Chen X, Chaleff S, Kotb M, Gillies SD King M, Mangada J, et al (2005) Human lymphoid and myeloid cell development in NOD/LtSz-scid IL2R gamma null mice engrafted with mobilized human hemopoietic stem cells. J Immunol 174: 6477-6489. doi:10.4049/jimmunol.174.10.6477

Smith MA, Maurin M, Cho HI, Becknell B, Freud AG, Yu J, Wei S, Djeu J, Celis E, Caligiuri MA, et al (2010) PRDM1/Blimp-1 controls effector cytokine production in human NK cells. J Immunol 185: 6058-6067. doi:10.4049/ jimmunol.1001682

Stegmann KA, Robertson F, Hansi N, Gill U, Pallant C, Christophides T, Pallett LJ, Peppa D, Dunn C, Fusai G, et al (2016) CXCR6 marks a novel subset of T-bet(lo)Eomes(hi) natural killer cells residing in human liver. Sci Rep 6: 26157. doi:10.1038/srep26157

Stonier SW, Schluns KS (2010) Trans-presentation: A novel mechanism regulating IL-15 delivery and responses. Immunol Lett 127: 85-92. doi:10.1016/j.imlet.2009.09.009 
Strowig T, Chijioke O, Carrega P, Arrey F, Meixlsperger S, Ramer PC, Ferlazzo G, Munz C (2010) Human NK cells of mice with reconstituted human immune system components require preactivation to acquire functional competence. Blood 116: 4158-4167. doi:10.1182/blood-2010-02-270678

von Freeden-Jeffry U, Vieira P, Lucian LA, McNeil T, Burdach SE, Murray R (1995) Lymphopenia in interleukin (IL)-7 gene-deleted mice identifies IL-7 as a nonredundant cytokine. J Exp Med 181: 1519-1526. doi:10.1084 / jem.181.4.1519

Vosshenrich CA, Garcia-Ojeda ME, Samson-Villeger SI, Pasqualetto V, Enault L, Richard-Le Goff O, Corcuff E, Guy-Grand D, Rocha B, Cumano A, et al (2006) A thymic pathway of mouse natural killer cell development characterized by expression of GATA-3 and CD127. Nat Immunol 7: 1217-1224. doi:10.1038/ni1395

Witte T, Wordelmann K, Schmidt RE (1990) Heterogeneity of human natural killer cells in the spleen. Immunology 69: 166-170.

Yamada D, Iyoda T, Shimizu K, Sato Y, Koseki H, Fujii S-I (2017) Efficient production of functional human NKT cells from induced pluripotent

stem cells: Reprogramming of human Va24+iNKT cells. Bio-Protocol 7: e2277. doi:10.21769/bioprotoc.2277

Yamada D, Iyoda T, Vizcardo R, Shimizu K, Sato Y, Endo TA, Kitahara G, Okoshi M, Kobayashi M, Sakurai M, et al (2016) Efficient regeneration of human Valpha24(+) invariant natural killer T cells and their antitumor activity in vivo. Stem Cells 34: 2852-2860. doi:10.1002/ stem.2465

Yawata M, Yawata N, Draghi M, Little AM, Partheniou F, Parham P (2006) Roles for HLA and KIR polymorphisms in natural killer cell repertoire selection and modulation of effector function. J Exp Med 203: 633-645. doi:10.1084/jem.20051884

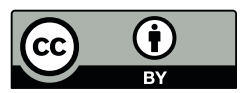

License: This article is available under a Creative Commons License (Attribution 4.0 International, as described at https://creativecommons.org/ licenses/by/4.0/). 